\title{
Using in-line milk progesterone data to characterize parameters of luteal activity and their association with fertility in Holstein cows
}

\author{
T. C. Bruinjé, ${ }^{1}$ M. G. Colazo, ${ }^{2}$ E. S. Ribeiro, ${ }^{3}$ M. Gobikrushanth, ${ }^{1}$ and D. J. Ambrose ${ }^{1,2 *}$ \\ ${ }^{1}$ Department of Agricultural, Food and Nutritional Science, University of Alberta, Edmonton, AB, Canada, T6G 2P5 \\ ${ }^{2}$ Livestock Research and Extension Branch, Alberta Agriculture and Forestry, Edmonton, AB, Canada, T6H 5T6 \\ ${ }^{3}$ Department of Animal Biosciences, University of Guelph, Guelph, ON, Canada, N1G 2W1
}

\section{ABSTRACT}

Our objectives were to characterize parameters of luteal activity based on milk progesterone concentration $(\mathrm{P} 4 \mathrm{c})$ data from before and after artificial insemination (AI) and to evaluate their potential association with fertility in Holstein cows. Records of AI events $(\mathrm{n}=4,353)$ and of milk $\mathrm{P} 4 \mathrm{c}(\mathrm{n}=158,961)$ obtained through an in-line milk analysis system (Herd Navigator, DeLaval International, Tumba, Sweden) from 1,891 lactations of 1,423 Holstein cows were evaluated. Milk P4c (ng/mL) were measured every $2.2 \pm 1.9 \mathrm{~d}$ (mean \pm standard deviation) between $23.6 \pm 7.3$ and $185.3 \pm 56.7 \mathrm{~d}$ in milk. Variations in milk P4c of consecutive records were used to determine onset of luteal phase (increase in $\mathrm{P} 4 \mathrm{c}$ from $<5.0$ to $\geq 5.0 \mathrm{ng} / \mathrm{mL}$ ), luteal phase length (period, in days, of $\mathrm{P} 4 \mathrm{c} \geq 5.0 \mathrm{ng} / \mathrm{mL}$ ), cessation of luteal phase (decline from $\geq 5.0$ to $<5.0 \mathrm{ng} / \mathrm{mL}$, designated as $\mathrm{P} 4 \mathrm{c}$ decline), and pregnancy (AI followed by a luteal phase that remained uninterrupted until $50 \mathrm{~d}$ post-AI). The length of the luteal phase preceding AI, the highest $\mathrm{P} 4 \mathrm{c}$ ( $\mathrm{P} 4 \mathrm{c}$ peak) during the luteal phase preceding AI, the lowest P4c preceding AI (P4c pre-AI) that followed a $\mathrm{P} 4 \mathrm{c}$-decline, and the interval between $\mathrm{P} 4 \mathrm{c}$-decline and AI were evaluated, as well as the interval between AI and onset of luteal phase, and $\mathrm{P} 4 \mathrm{c}$ at early diestrus (4.5 $\pm 0.6 \mathrm{~d}$ post-AI), mid diestrus $(10.0 \pm 0.6 \mathrm{~d}$ post-AI $)$, and late diestrus $(14.1 \pm 0.6 \mathrm{~d}$ post-AI). Data were analyzed using logistic regressions, and comparisons made based on quartiles and cut-points established by receiver operating characteristic curve analysis. Overall probability of pregnancy was $32.0 \%$. Parameters associated with reduced probability of pregnancy (represented as percentage points decrease in the probability of pregnancy) were (1) luteal phase length $>14.4$ d (7.6\% decrease), (2) P4c peak $\leq 24.7 \mathrm{ng} / \mathrm{mL}(4.5 \%$ decrease), (3) P4c pre-AI $>0.5 \mathrm{ng} / \mathrm{mL}$ (5.5\% decrease),

Received February 27, 2018.

Accepted September 7, 2018.

*Corresponding author: divakar.ambrose@gov.ab.ca
(4) interval between P4c-decline and $\mathrm{AI}$ of $>1.6 \mathrm{~d}(4.0 \%$ decrease), (5) interval between $\mathrm{AI}$ and onset of luteal phase of $<7$ or $>11 \mathrm{~d}$ (9.3 and $12.1 \%$ decrease, respectively), and (6) P4c at early diestrus $\leq 0.7$ or $>3.5 \mathrm{ng} /$ $\mathrm{mL}$ (15.2 and $6.7 \%$ decrease, respectively), (7) P4c at mid diestrus $\leq 12.4 \mathrm{ng} / \mathrm{mL}$ (12.5\% decrease), and (8) $\mathrm{P} 4 \mathrm{c}$ at late diestrus $\leq 22.7 \mathrm{ng} / \mathrm{mL}$ (9.7\% decrease). The parameters of luteal activity associated with reduced probability of pregnancy established here could be used as benchmarks while developing recommendations to improve reproductive performance in herds using inline milk progesterone monitoring.

Key words: luteal phase, ovarian activity, pregnancy, reproductive performance

\section{INTRODUCTION}

Reproductive efficiency is one of the main aspects influencing the profitability of dairy operations. An increase in the proportion of cows conceiving soon after the elective waiting period will decrease the proportion of cows with extended lactations; such cows are less profitable in later stages of lactation (Ribeiro et al., 2012). The increase in genetic merit for milk production over the past decades has been associated with an overall decrease in reproductive performance of dairy cows (Lucy, 2001). Although increased milk production per se is not necessarily detrimental to fertility (LeBlanc, 2013), the increased DMI and liver blood flow and consequently the greater metabolic clearance rate in high-producing cows is associated with reduced peripheral concentrations of steroid hormones (Sangsritavong et al., 2002). Reduced concentrations of hormones such as estradiol and progesterone $(\mathbf{P} 4)$ affect the hypothalamus-pituitary-ovarian axis (Wiltbank et al., 2006) and uterine physiology of the cow (Geisert et al., 1992). For instance, high milk production is associated with reduced concentrations of circulating estradiol and shorter duration of estrus (Lopez et al., 2004). These factors may, at least partially, explain the poor reproductive performance reported in modern dairy herds in North America. 
To overcome poor reproductive performance, protocols for synchronization of ovulation and timed-AI (Pursley et al., 1995), estrus activity monitors (Valenza et al., 2012), and more recently, an in-line milk P4 analysis system (Friggens and Chagunda, 2005; DeLaval International, 2011) have been developed for improved reproductive management of dairy herds. The in-line milk analysis system (IMAS) is an electronic tool that automatically samples and quantifies milk P4 concentrations (P4c), on average every $2 \mathrm{~d}$, using a biosensor technology. Based on variations in milk P4c, the IMAS identifies both the onset and end of luteal phases, determining estrus and pregnancy status. Although the biomodel used by the IMAS has been mainly designed to identify onset of estrus (Friggens et al., 2008; DeLaval International, 2011), the frequent milk sampling starting approximately $3 \mathrm{wk}$ postpartum and continuing until pregnancy is determined (at approximately $50 \mathrm{~d}$ post-AI) provides an opportunity to characterize luteal activity in individual cows and evaluate its associations with fertility.

Using such data, recent studies from our research group examined associations of early postpartum luteal activity (Bruinjé et al., 2017a) and pre- and post-AI P4c profiles (Bruinjé et al., 2017b) with parity and fertility. Parameters such as delayed commencement of postpartum luteal activity and the occurrence of abnormal luteal phases before first AI are known to be negatively associated with fertility (Lamming and Darwash, 1998; Ranasinghe et al., 2011; Bruinjé et al., 2017a). However, relationships between specific variables of luteal function obtained by an automated IMAS (such as length of the luteal phase preceding estrus, interval between variations in $\mathrm{P} 4 \mathrm{c}$ and $\mathrm{AI}$, and $\mathrm{P} 4 \mathrm{c}$ at different time points) and fertility have not been investigated.

Therefore, the objectives were to characterize and evaluate variables of luteal activity and their associations with fertility in Holstein cows based on milk P4c data obtained before and after AI. Specifically, we examined the associations between (1) length of the luteal phase preceding AI, (2) interval between decline in P4c and AI, (3) interval between AI and onset of subsequent luteal phase, and (4) P4c at different time points before and after AI, and the probability of pregnancy.

\section{MATERIALS AND METHODS}

\section{In-Line Milk Progesterone Analysis System and Records Description}

Milk P4c records ( $\mathrm{n}=195,931)$ generated by an automated IMAS (Herd Navigator, DeLaval International, Tumba, Sweden, and Lattec/IS, Hillarød, Denmark) were initially obtained from a total of 2,264 Holstein cows (3,693 lactations) in 4 commercial dairy herds (A, B, C, and D) in Alberta, Canada, from March 2014 to December 2016. The 4 herds used the IMAS as the primary reproductive management tool, and most AI were performed at spontaneous estrus determined based on P4c profiles, as further described. Herd demographics such as number of AI events and postpartum milk P4c sampling range of the final data set are presented in Table 1. Among the AI data, $49.8 \%$ were obtained from herd $\mathrm{B}$, whereas $30.4,12.8$, and $7.0 \%$ were obtained from herds A, C, and D, respectively. Overall, 41.9, 28.6 , and $29.5 \%$ of the AI events were from first, second, and third or greater parity cows, respectively. On average, the first and last postpartum milk $\mathrm{P} 4 \mathrm{c}$ were determined at $23.6 \pm 7.3$ and $185.3 \pm 56.7$ DIM (mean $\pm \mathrm{SD})$.

Milk P4c measurement started at $21.8 \pm 4.4,21.3$ \pm 3.1 , and $21.7 \pm 4.7$ DIM in herds $\mathrm{A}, \mathrm{B}$, and $\mathrm{C}$, respectively. In herd $\mathrm{D}$, milk $\mathrm{P} 4 \mathrm{c}$ measurement started at $42.3 \pm 2.8$ DIM because a management decision to adopt a prolonged elective waiting period was followed. Following first milk P4c measurement, sampling repeated at algorithm-driven intervals on average every $2.2 \pm 1.9 \mathrm{~d}$ based on a biomodel described in detail by Friggens and Chagunda (2005) and reported elsewhere (Friggens et al., 2008; Tenghe et al., 2015; Bruinjé et al., 2017a,b). In brief, the biomodel sampling frequency aims to estimate the day of estrus based on the decline in milk $\mathrm{P} 4 \mathrm{c}$ below a default threshold, indicating the cessation of the previous luteal phase. Because of potential differences between batches of dry sticks used for the assay and in temperature/humidity, actual milk P4c are adjusted based on a model that controls for expected random noise (Friggens and Chagunda, 2005). This adjustment allows the biomodel to more accurately distinguish between high and low P4c phases, using a $5.0 \mathrm{ng} / \mathrm{mL}$ cut-off value for adjusted P4c.

The adjusted $\mathrm{P} 4 \mathrm{c}$ values and cut-off of $5.0 \mathrm{ng} / \mathrm{mL}$ were established by the IMAS based on proprietary calculations to identify variations in $\mathrm{P} 4 \mathrm{c}$ for each cow. The day of the decline in $\mathrm{P} 4 \mathrm{c}$ from above to below the $5.0 \mathrm{ng} / \mathrm{mL}$ cut-off for adjusted $\mathrm{P} 4 \mathrm{c}$ (referred to as $\mathrm{P} 4 \mathrm{c}$-decline) was considered as the reference point for each $\mathrm{P} 4 \mathrm{c}$ profile to determine subsequent sampling frequency. Once a $\mathrm{P} 4 \mathrm{c}$-decline was determined, a notification of estrus occurred in the IMAS software and AI was recommended by the manufacturer to occur within 24 to 36 h (DeLaval International, 2011). After $\mathrm{P} 4 \mathrm{c}$-decline, the sampling frequency was calculated by the biomodel to trigger the subsequent samples. Then, 4 samples were expected to occur at approximately 5, 9, 14, and $18 \mathrm{~d}$ after P4c-decline, followed by daily samples between 18 and $25 \mathrm{~d}$, or until the next P4cdecline. If $\mathrm{P} 4 \mathrm{c}$ was above $10.0 \mathrm{ng} / \mathrm{mL}$ at $25 \mathrm{~d}$ after $\mathrm{P} 4 \mathrm{c}-$ 
Table 1. Summary of AI events, and descriptive statistics of herd performance and DIM to first and last milk progesterone concentration (P4c) record

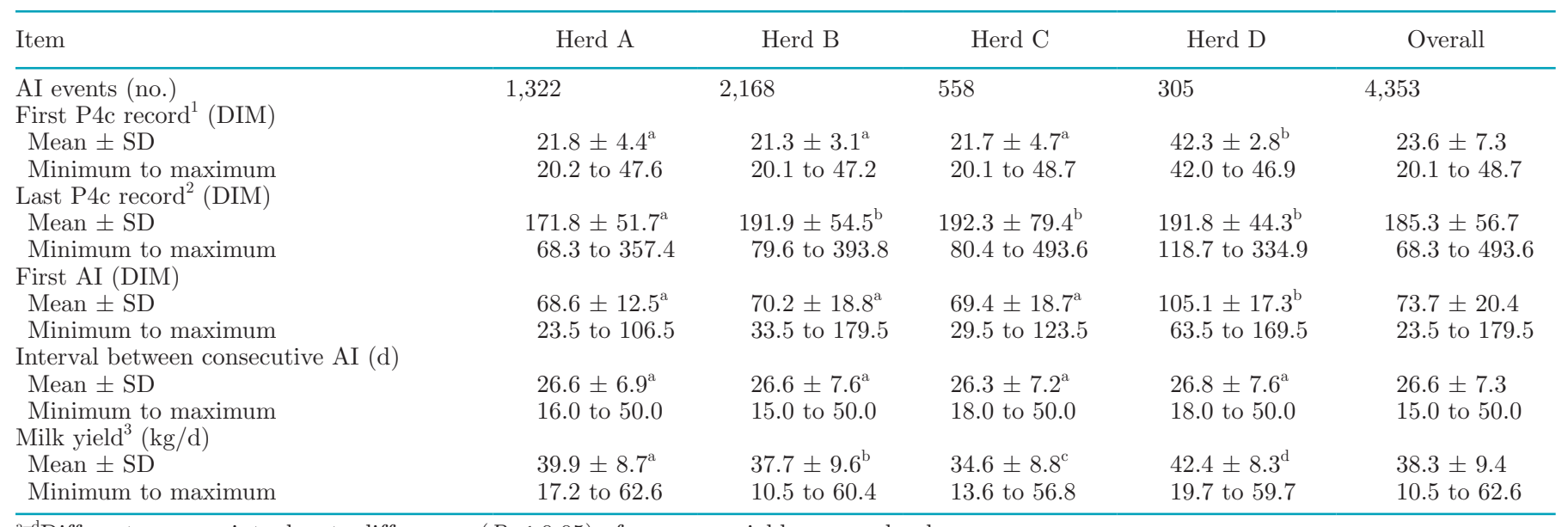

${ }^{\mathrm{a}-\mathrm{d}}$ Different superscripts denote differences $(P \leq 0.05)$ of a same variable among herds.

${ }^{1}$ Days in milk when the first milk P4c record was obtained in the postpartum period.

${ }^{2}$ Days in milk when the last milk $\mathrm{P} 4 \mathrm{c}$ record was obtained in the postpartum period.

${ }^{3}$ Average daily milk yield $(\mathrm{kg} / \mathrm{d})$ between 10 and 60 DIM.

decline, samples were taken every second day until P4c dropped below $10.0 \mathrm{ng} / \mathrm{mL}$, then samples were taken daily until the next P4c-decline (in the event of nonpregnancy). Once the subsequent $\mathrm{P} 4 \mathrm{c}$-decline occurred, the sampling frequency was re-calculated for the next cycle. By evaluating this sampling biomodel, Friggens et al. (2008) reported $93.3 \%$ sensitivity (Se) and $93.7 \%$ specificity (Sp) for detection of estrus when comparing to P4c profiles of estruses at which AI resulted in confirmed pregnancies, although they used a different assay for determining $\mathrm{P} 4 \mathrm{c}$ and consequently a different cut-off $(4.0 \mathrm{ng} / \mathrm{mL})$ for $\mathrm{P} 4 \mathrm{c}$-decline.

The biomodel was also designed to estimate pregnancy status based on $\mathrm{P} 4 \mathrm{c}$ profiles post-AI. If an AI event had been recorded within $5 \mathrm{~d}$ after $\mathrm{P} 4 \mathrm{c}$-decline, sampling was standard until $25 \mathrm{~d}$, then was taken every 2 to $3 \mathrm{~d}$ between 25 and $30 \mathrm{~d}$, and every $5 \mathrm{~d}$ between 30 and $55 \mathrm{~d}$ after $\mathrm{P} 4 \mathrm{c}$-decline. If $\mathrm{P} 4 \mathrm{c}$ remained uninterrupted above the $5.0 \mathrm{ng} / \mathrm{mL}$ cut-off until approximately $55 \mathrm{~d}$, pregnancy was assumed by the IMAS and sampling stopped.

Each $\mathrm{P} 4 \mathrm{c}$ record contained corresponding information of herd, cow, parity, sampling date and time, DIM, and actual P4c, adjusted $\mathrm{P} 4 \mathrm{c}$, and slope of $\mathrm{P} 4 \mathrm{c}$ among 3 consecutive records. Chronological events were coded using Excel (Microsoft Corp., Redmond, WA) conditional algorithms to identify the first milk $\mathrm{P} 4 \mathrm{c}$ record of the lactation, the last milk $\mathrm{P} 4 \mathrm{c}$ record of the lactation, the sampling interval between consecutive milk P4c records, and the day of events related to variation in adjusted milk $\mathrm{P} 4 \mathrm{c}$ (below vs. above the pre-determined cut-off of $5.0 \mathrm{ng} / \mathrm{mL}$ ). The day in which milk P4c increased above the cut-off and was followed by at least one consecutive record above the cut-off was set as the onset of luteal phase. The luteal phase length was defined as the number of days of uninterrupted adjusted $\mathrm{P} 4 \mathrm{c}$ values above or equal to $5.0 \mathrm{ng} / \mathrm{mL}$ until a P4c-decline to less than $5.0 \mathrm{ng} / \mathrm{mL}$, indicating the cessation of the luteal phase. The interval, in days, between the P4c-decline and onset of subsequent luteal phase was defined as the inter-luteal phase length, and the interval between 2 consecutives $\mathrm{P} 4 \mathrm{c}$-decline events preceding AI was defined as the cycle length.

\section{Filtering Criteria}

The total milk P4c records initially obtained included every record available from the IMAS software during the study period. Similar to previous studies evaluating milk P4c data (Friggens et al., 2008; Tenghe et al., 2015), sets of filtering criteria were applied to the data both at a lactation level and at a variable level. The filtering aimed to exclude lactations that had prolonged periods of no $\mathrm{P} 4 \mathrm{c}$ measurements (i.e., gaps in sampling) that could occur if a cow had temporarily not been assigned to be sampled by the IMAS for management reasons, or if the system had a temporary breakdown during any time of a lactation period. If such sampling gaps were not considered, they would cause inaccurate estimation of $\mathrm{P} 4 \mathrm{c}$ profiles.

At a lactation level, if the first $\mathrm{P} 4 \mathrm{c}$ record was obtained later than 50 DIM, or if the outcome of AI was not known, all records from those lactations were excluded. At a variable level: (1) if there was a gap lon- 


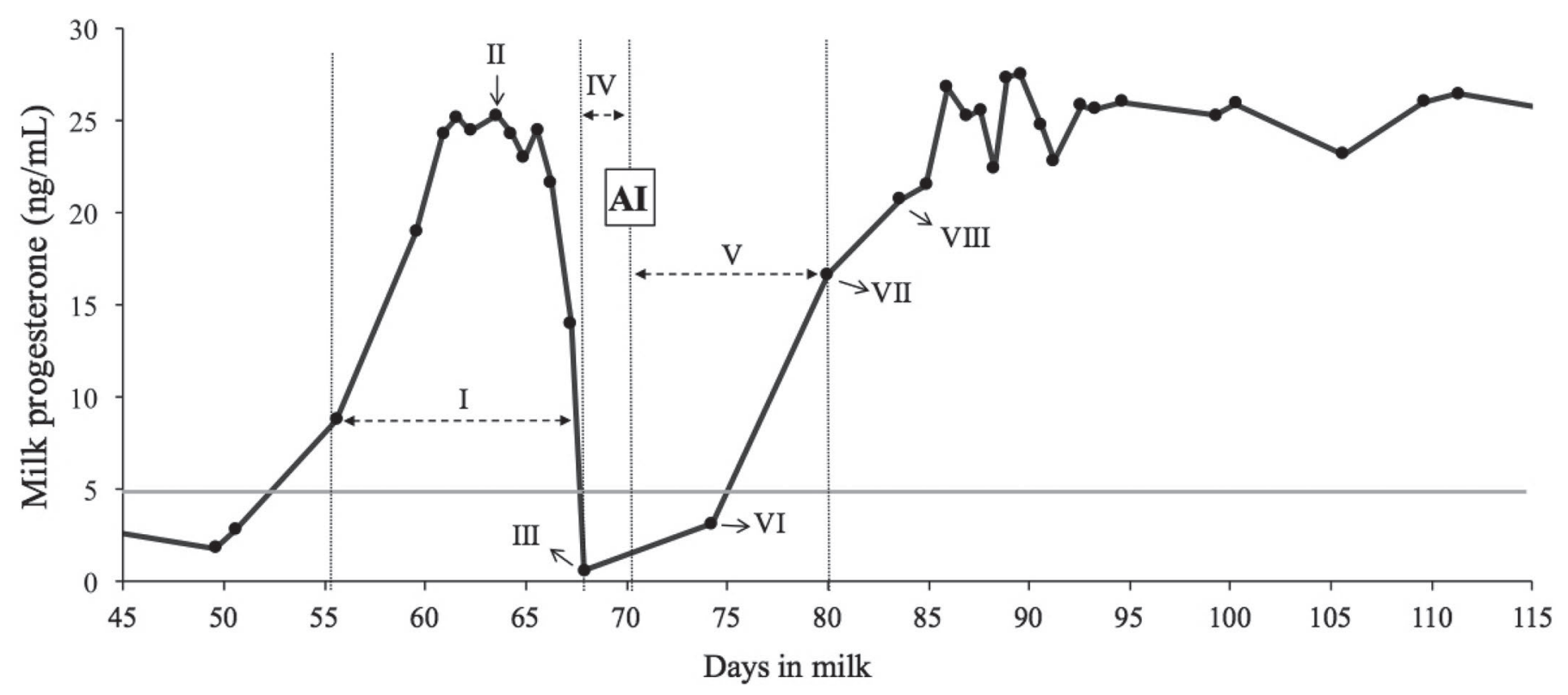

Figure 1. Milk progesterone concentration (P4c) profile of a hypothetical cow that, based on the standard cut-off value of $5.0 \mathrm{ng} / \mathrm{mL}$ for luteal activity, had an onset of luteal phase at 55 DIM (day of milk P4c measurement $\geq 5.0 \mathrm{ng} / \mathrm{mL}$ ), a P4c-decline at 68 DIM, received an AI at 70 DIM, had an onset of luteal phase at 80 DIM, and had an uninterrupted luteal phase until 115 DIM. Indicators I to IV represent variables before AI: I = luteal phase length $(\mathrm{d})$; II = P4c peak $(\mathrm{ng} / \mathrm{mL}) ; \mathrm{III}=\mathrm{P} 4 \mathrm{c}$ pre-AI $(\mathrm{ng} / \mathrm{mL}) ; \mathrm{IV}=$ interval between P4c-decline and AI $(\mathrm{d})$. Indicators V to VIII represent variables after AI: V = interval between AI and onset of luteal phase (d); VI $=\mathrm{P} 4 \mathrm{c}$ at early diestrus $(4.5 \pm 0.6$ $\mathrm{d}$ post-AI $) ; \mathrm{VII}=\mathrm{P} 4 \mathrm{c}$ at mid diestrus $(10.0 \pm 0.6 \mathrm{~d}$ post-AI $)$; and $\mathrm{VIII}=\mathrm{P} 4 \mathrm{c}$ at late diestrus $(14.1 \pm 0.6 \mathrm{~d}$ post-AI $)$.

ger than $8 \mathrm{~d}$ during an ongoing luteal phase, or a gap longer than $4 \mathrm{~d}$ in the last 3 milk $\mathrm{P} 4 \mathrm{c}$ records preceding a P4c-decline, all records from that luteal phase were excluded; (2) if there was a gap longer than $8 \mathrm{~d}$ during an inter-luteal phase, all records from that inter-luteal phase were excluded; and (3) if a luteal phase or an inter-luteal phase had only one $\mathrm{P} 4 \mathrm{c}$ record, variables respective to those phases were excluded.

The filtering criteria also excluded any AI event (and corresponding $\mathrm{P} 4 \mathrm{c}$ records) that did not occur based on IMAS P4c profiles due to management decisions. For instance, some cows in herd A were preassigned by the herd manager to a timed-AI protocol, and reproductive decisions occurred irrespective of the IMAS. Therefore, records of $\mathrm{P} 4 \mathrm{c}$ corresponding to $\mathrm{P} 4 \mathrm{c}$ profiles before and after AI events that occurred following a timed-AI protocol, or that received any hormonal intervention, were excluded. In addition, AI events and corresponding P4c records were excluded if 2 consecutive AI events occurred within the same inter-luteal phase period, if an AI was not preceded by a P4c-decline within $5 \mathrm{~d}$, or if it was not followed by an onset of luteal phase.

To improve precision in estimating the luteal activity variables, those that were defined based on the interval between consecutive events (i.e., interval between onset of luteal phase and P4c-decline, interval between P4cdecline and AI, and between AI and onset of luteal phase) that showed skewness values less than -2 or more than 2 , had their extreme $1 \%$ values considered as outliers and excluded. The final data set contained 4,353 AI events respective to 1,891 lactations of 1,423 cows.

\section{Description of Variables}

Luteal Phase Length. The luteal phase length was defined as the number of days of uninterrupted adjusted $\mathrm{P} 4 \mathrm{c}$ greater than or equal to $5.0 \mathrm{ng} / \mathrm{mL}$ until it declined to less than $5.0 \mathrm{ng} / \mathrm{mL}$ followed by AI (indicator I, Figure 1), and determined by subtracting the date of $\mathrm{P} 4 \mathrm{c}$-decline from the date which the luteal phase initiated.

$P 4 c$ Peak. The P4c peak was defined as the highest actual $\mathrm{P} 4 \mathrm{c}$ recorded in the last $8 \mathrm{~d}$ of the luteal phase preceding an AI event (indicator II, Figure 1), as the last $8 \mathrm{~d}$ of the luteal phase preceding AI was the period with increased sampling frequency (Table 2). Within that 8-d range, $5.6 \pm 2.1$ (mean $\pm \mathrm{SD}$ ) $\mathrm{P} 4 \mathrm{c}$ records were obtained with an average sampling interval of 1.3 $\pm 0.6 \mathrm{~d}$ between records.

P4c Pre-AI. The P4c pre-AI was defined as the single record of actual $\mathrm{P} 4 \mathrm{c}$ less than $5.0 \mathrm{ng} / \mathrm{mL}$ preceding $\mathrm{AI}$, that indicated the cessation of the luteal phase preceding AI (indicator III, Figure 1).

Interval Between P4c-decline and AI. The interval, in days, between the time of $\mathrm{P} 4 \mathrm{c}$-decline and the 
Table 2. Descriptive statistics including mean $\pm \mathrm{SD}$, minimum and maximum (min. to max.) values, and percentiles (25th, 50th, 75th) of interval in days between consecutive milk progesterone concentration $(\mathrm{P} 4 \mathrm{c})$ records within different stages of $\mathrm{P} 4 \mathrm{c}$ profiles

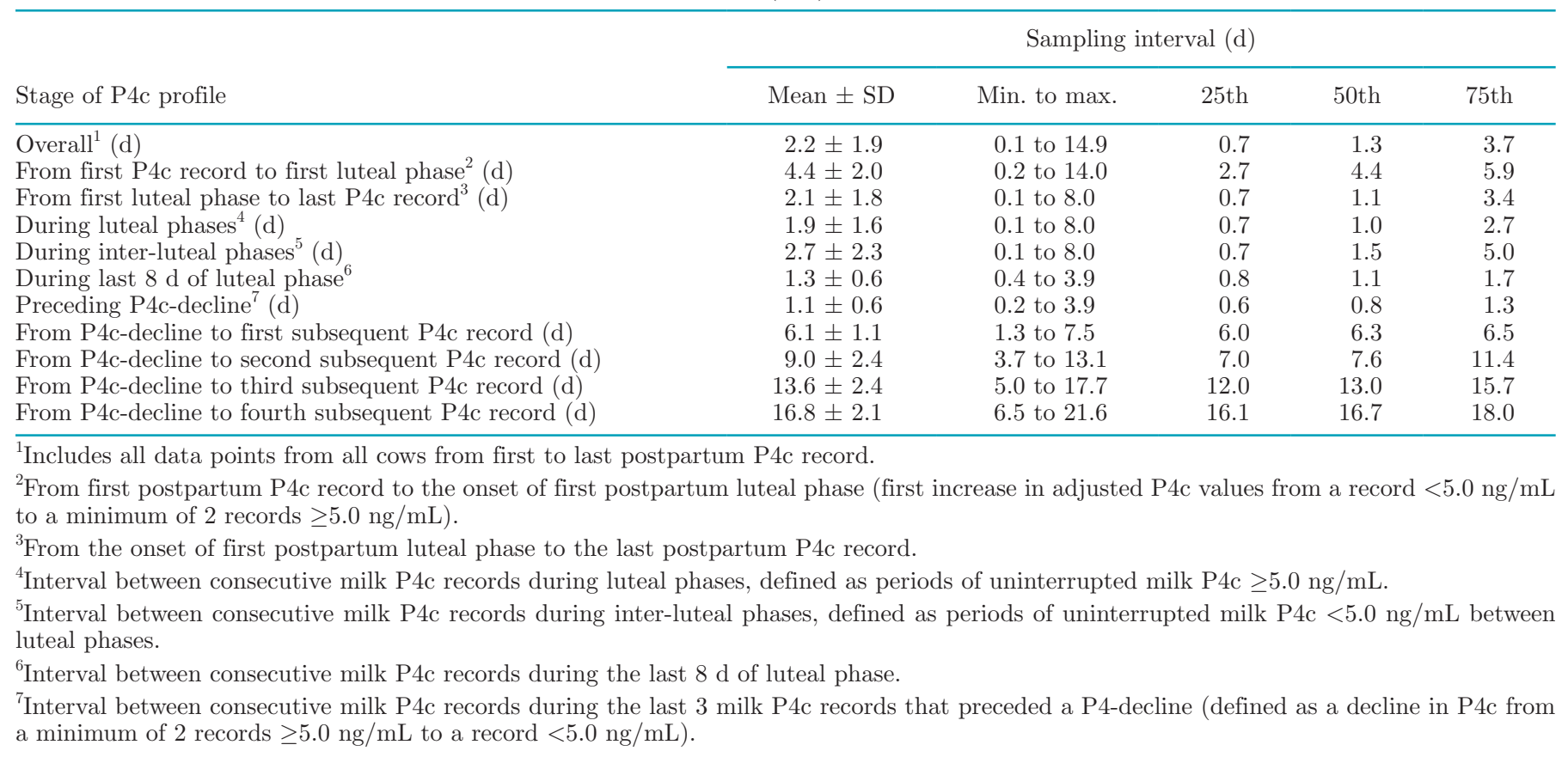

time of AI (indicator IV, Figure 1). Milk P4c records included information of date and time of sampling, but only date was available for AI events; thus, the time of AI was established as $1200 \mathrm{~h}$ because most of the AI occurred between 0800 and $1600 \mathrm{~h}$.

Interval Between AI and Onset of Luteal Phase. The interval, in days, between the time of AI (d 0) and the time of onset of subsequent luteal phase (i.e., first adjusted $\mathrm{P} 4 \mathrm{c}$ greater than or equal to 5.0 $\mathrm{ng} / \mathrm{mL}$ after AI; indicator V, Figure 1). As the sampling frequency after AI was reduced and usually only 3 samples were expected during the first $15 \mathrm{~d}$ following $\mathrm{AI}$, the interval between $\mathrm{AI}$ and onset of luteal phase was also categorized as occurring between 3 and $6 \mathrm{~d}$, between 7 and $11 \mathrm{~d}$, or beyond $12 \mathrm{~d}$ post-AI.

P4c at Early, Mid, and Late Diestrus. The 3 single $\mathrm{P} 4 \mathrm{c}$ records obtained between 3 and 6 (4.5 \pm $0.6)$, between 7 and $11(10.0 \pm 0.6)$, and between 12 and $15(14.1 \pm 0.6)$ d post-AI were defined as P4c at early, mid, and late diestrus, respectively (indicators VI, VII, and VIII, Figure 1).

Slopes in $\mathrm{P} 4 \mathrm{c}$ (change among 3 consecutive records; $\mathrm{ng} / \mathrm{mL}$ ) automatically calculated by the IMAS were obtained respective to the $3 \mathrm{P} 4 \mathrm{c}$ records preceding $\mathrm{AI}$ (P4c slope pre-AI), preceding mid diestrus (P4c slope to mid diestrus), and preceding late diestrus (P4c slope to late diestrus). As no $\mathrm{P} 4 \mathrm{c}$ record was expected between the record indicative of $\mathrm{P} 4 \mathrm{c}$ pre- $\mathrm{AI}$ and the record indicative of early diestrus, the $\mathrm{P} 4 \mathrm{c}$ slope to early diestrus was not estimated. Additional variables evaluated were the sampling interval preceding $\mathrm{P} 4 \mathrm{c}$-decline, defined as the average interval (in days) between consecutive milk $\mathrm{P} 4 \mathrm{c}$ records among the last 3 records that preceded the $\mathrm{P} 4 \mathrm{c}$-decline, and milk yield during AI, defined as the average daily milk yield $(\mathrm{kg} / \mathrm{d})$ in the $4 \mathrm{~d}$ before and after AI.

Once an AI event was entered into the software, the IMAS biomodel adjusted the sampling frequency and was programmed to obtain samples until approximately $50 \mathrm{~d}$ post-AI (Friggens and Chagunda, 2005) unless interrupted by a P4c-decline. Thus, similar to previous studies that evaluated IMAS data (Bruinjé et al., 2017a,b), the present study determined pregnancy status exclusively based on P4c profiles post-AI. Pregnancy was declared if the post-AI luteal phase remained uninterrupted until $50 \mathrm{~d}$, and nonpregnancy was declared if the luteal phase post-AI was interrupted (P4cdecline) within $50 \mathrm{~d}$. During the study period, herds $\mathrm{B}, \mathrm{C}$, and D had ultrasound confirmation by the herd veterinarian at approximately $50 \mathrm{~d}$ post-AI in cows assumed pregnant based on P4c profiles post-AI. In herd A, pregnancies were declared exclusively based on the IMAS P4c profiles post-AI. For this herd, the accuracy of determining pregnancy at $50 \mathrm{~d}$ post-AI exclusively based on P4c profiles was evaluated in AI events that had the subsequent calving date available $(\mathrm{n}=549)$. Based on the expected range of gestation length for Holstein cows (Vieira-Neto et al., 2017), a calving that 
occurred 256 to 296 d after AI was retrospectively considered as the gold standard criterion for pregnancy determination. The positive and negative predictive values for pregnancy determination based on $\mathrm{P} 4 \mathrm{c}$ profiles at $50 \mathrm{~d}$ post-AI was 97.2 and $98.3 \%$, respectively, resulting in accuracy of $97.8 \%$. In the present data set, the interval (mean $\pm \mathrm{SD}$ ) between $\mathrm{AI}$ and the last $\mathrm{P} 4 \mathrm{c}$ record measured in pregnant cows was $55.5 \pm 5.9$ d. The average luteal phase length (mean \pm SD) in cows considered nonpregnant was $13.9 \pm 6.4 \mathrm{~d}$.

\section{Statistical Analysis}

All analyses were performed with SAS 9.4 (Studio 3.5 platform, SAS Institute Inc., Cary, NC). The MEANS and UNIVARIATE procedures were used to obtain descriptive statistics of herd demographics, sampling frequency, and luteal activity variables. Comparisons of continuous variables respective to herd description were analyzed by mixed effects ANOVA using the GLIMMIX procedure, including cow as a random effect, posthoc tests performed using Tukey-Kramer adjustment, and values presented as mean \pm standard deviation of the mean. Relationships among continuous variables were assessed by Pearson correlation coefficient tests using the CORR procedure. To evaluate the proportion of total variance of each luteal activity variable attributed to between-animal variance, repeatability estimates were obtained by ANOVA and calculated as $\sigma^{2}$ between-animal

\section{$\left(\sigma^{2}\right.$ between-animal $+\sigma^{2}$ within-animal $)$}

The outcome of interest was pregnancy outcome, which was analyzed as a binary variable (pregnant vs. nonpregnant) using logistic regression models with the GLIMMIX procedure. Event of AI was considered the experimental unit. An initial exploratory model was built including the fixed effects of herd (A, B, C, D), year $(2014,2015,2016)$, season at AI [winter (December, January, February), spring (March, April, May), summer (June, July, August), fall (September, October, November)], parity (first, second, third or greater), milk yield during AI, and number of $\mathrm{AI}$ as a covariate. Then, multivariable models were built for each continuous variable respective to $\mathrm{P} 4 \mathrm{c}$ profiles, which were evaluated for both linear and quadratic effects. Models included the fixed effects of year, season at AI, parity, interaction between luteal activity variable and parity, milk yield during AI, and number of AI as a covariate, in addition to herd as a random effect. Independent variables were then selected based on manual backward stepwise elimination, until all remaining variables had $P \leq 0.10$ in each final model. Odds ratio and confidence interval estimates for continuous variables were as- sessed using one standard deviation unit offset from the mean. Curves for predicted probability of pregnancy for each luteal activity variable were generated from the respective final mixed models using the BLUP and inverse link functions.

Continuous variables were both categorized into quartiles (below 25th percentile, between 25th percentile and median, between median and 75th percentile, and above 75 th percentile), and analyzed against pregnancy outcome to obtain receiver operating characteristic (ROC) curves using the LOGISTIC procedure. The ROC analysis generates a curve that accounts for Se (proportion of AI with the outcome of "pregnant" that was above a cut-point) and Sp (proportion of AI with the outcome of "nonpregnant" that was below a cut-point) to identify the optimal cut-point for each variable that best predict pregnancy. The Youden index (i.e., the point in the ROC curve that had the largest combined Se and $1-\mathrm{Sp}$ ) and the area under the curve (AUC) were obtained for each variable, and variables were categorized as below $(\leq)$ or above $(>)$ the cut-point.

Finally, multivariable logistic regression models were built including the fixed effects previously described, each categorized luteal activity variable, interaction between luteal activity variable and parity, and number of AI as a covariate, with herd kept as a random effect. Independent variables were selected by backward stepwise elimination, until all remaining variables had $P \leq 0.10$ in the final models. The inverse link function was used to obtain estimates on the inverse linked scale for predicted probabilities means of pregnancy, odds ratio, and confidence interval. For all comparisons, $P$ $\leq 0.05$ was considered significant, whereas $0.05<P \leq$ 0.10 was considered a tendency.

\section{RESULTS}

\section{Herds, Sampling, and Data Description}

Mean $( \pm \mathrm{SD})$ DIM to first AI were similar for herds $\mathrm{A}, \mathrm{B}$, and $\mathrm{C}(68.6 \pm 12.5,70.2 \pm 18.8$, and $69.4 \pm$ 18.7 , respectively) but greater in herd D $(105.1 \pm 17.3)$. Summary of AI events and P4c records, and descriptive statistics of herd performance such as sampling range, DIM to first postpartum AI, interval between consecutive AI, and milk yield during AI are presented in Table 1.

As previously described, the IMAS biomodel is designed to take samples for $\mathrm{P} 4 \mathrm{c}$ measurement at predetermined intervals according to the reference point of $\mathrm{P} 4 \mathrm{c}$-decline. The intervals between consecutive milk $\mathrm{P} 4 \mathrm{c}$ records obtained within different stages of $\mathrm{P} 4 \mathrm{c}$ profiles are presented in Table 2. 
An interval of greater than $2 \mathrm{~d}$ between consecutive $\mathrm{P} 4 \mathrm{c}$ records during the last 3 records preceding $\mathrm{P} 4 \mathrm{c}$-decline occurred in $10 \%$ of the $\mathrm{P} 4 \mathrm{c}$ profiles. All evaluated AI were preceded by a P4c-decline below the cut-off of $5.0 \mathrm{ng} / \mathrm{mL}$ for adjusted $\mathrm{P} 4 \mathrm{c}$, and $95 \%$ had actual $\mathrm{P} 4 \mathrm{c}$ pre-AI less than $1.5 \mathrm{ng} / \mathrm{mL}$.

The mean $( \pm \mathrm{SD})$ interval between $\mathrm{P} 4 \mathrm{c}$-decline and onset of luteal phase (i.e., inter-luteal phase) was 12.0 $\pm 3.7 \mathrm{~d}$, whereas the luteal phase length averaged 13.7 \pm 6.2 d. The average interval between 2 consecutive $\mathrm{P} 4 \mathrm{c}$-decline events that preceded $\mathrm{AI}$, indicating the cycle length, was $25.6 \pm 6.6 \mathrm{~d}$, and the $25 \mathrm{th}, 50 \mathrm{th}$, and 75 th percentiles were $21.8,23.7$, and $26.7 \mathrm{~d}$, respectively. Repeatability estimates $(P<0.01)$ for inter-luteal phase, luteal phase, and cycle length were $0.09,0.16$, and 0.12 , respectively. Descriptive statistics of luteal activity variables used to evaluate associations with the probability of pregnancy, and respective repeatability estimates, are presented in Table 3.

Initial exploratory analysis showed that herd $(P<$ $0.001)$, year $(P<0.01)$, and parity $(P=0.04)$ were factors influencing the probability of pregnancy. The overall predicted probability of pregnancy was $32.0 \%$ and varied $(P<0.001)$ among herds, with $34.4,19.3,30.8$, and $49.8 \%$ probability of pregnancy for herds A, B, C, and $\mathrm{D}$, respectively. The greatest number of AI events were obtained from herd B $(49.8 \%)$, which had the lowest $(P<0.001)$ probability of pregnancy among herds. The probability of pregnancy was reduced $(P<0.01)$ in $2016(28.6 \%)$ compared with $2015(33.4 \%)$ and 2014
$(36.3 \%)$. Cows of third or greater parity had reduced $(P=0.01)$ probability of pregnancy $(29.9 \%)$ than first parity cows $(34.5 \%)$ and tended to have reduced $(P=$ $0.06)$ probability of pregnancy compared with second parity cows $(33.7 \%)$. There were no significant effects of season, milk yield during AI, or number of AI on the probability of pregnancy, and no significant interactions between luteal activity variables before or after AI and parity were evident. Pearson correlation coefficients of relationships among variables, including milk yield during AI and lactation number, are presented in Table 4.

\section{Variables Before Al Associated with the Probability of Pregnancy}

A negative linear relationship $(P<0.001)$ was observed between luteal phase length and the probability of pregnancy (Figure 2a). Based on ROC curve analysis, the cut-point of luteal phase length that best predicted $(P<0.001)$ the probability of pregnancy was $14.4 \mathrm{~d}$ (Se: 0.74, Sp: 0.33, AUC: 0.54), and AI following luteal phase of $>14.4 \mathrm{~d}$ (above the cut-point) or $>15.3 \mathrm{~d}$ (Q4, mean $21.8 \mathrm{~d})$ resulted in reduced $(P<0.01)$ probability of pregnancy (Table 5).

The $\mathrm{P} 4 \mathrm{c}$ peak was positively associated $(P=0.01)$ with the probability of pregnancy (Figure 2b). Although with low accuracy, the cut-point of $\mathrm{P} 4 \mathrm{c}$ peak that predicted pregnancy with the largest combined Se and Sp $(P<0.001)$ was $24.7 \mathrm{ng} / \mathrm{mL}$ (Se: 0.59, Sp: 0.47 , AUC: 0.53$)$. The probability of pregnancy was

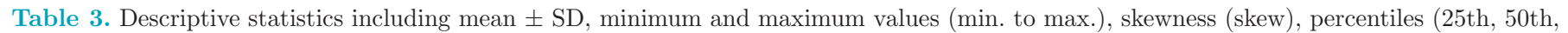
$75 \mathrm{th})$, and repeatability estimates (rep) of variables associated $(P \leq 0.05)$ with the probability of pregnancy

\begin{tabular}{|c|c|c|c|c|c|c|c|c|}
\hline Variable & No. & Mean $\pm \mathrm{SD}$ & Min. to max. & Skew & 25 th & 50 th & 75 th & $\operatorname{Rep}^{10}$ \\
\hline Luteal phase length ${ }^{1}$ (d) & 4,135 & $13.7 \pm 6.2$ & 1.5 to 43.3 & 1.8 & 10.0 & 12.4 & 15.3 & 0.16 \\
\hline $\mathrm{P} 4 \mathrm{c}$ peak $^{2}(\mathrm{ng} / \mathrm{mL})$ & 4,353 & $24.0 \pm 3.6$ & 5.0 to 28.0 & -1.7 & 22.7 & 25.0 & 26.5 & 0.20 \\
\hline $\mathrm{P} 4 \mathrm{c}$ pre-AI $\mathrm{AI}^{3}(\mathrm{ng} / \mathrm{mL})$ & 4,353 & $0.6 \pm 0.5$ & 0.1 to 4.6 & 3.0 & 0.3 & 0.5 & 0.7 & 0.03 \\
\hline $\mathrm{P} 4 \mathrm{c}$ slope pre-AI ${ }^{4}(\mathrm{ng} / \mathrm{mL})$ & 4,352 & $-5.9 \pm 2.0$ & -10.5 to -0.3 & 0.2 & -7.4 & -5.9 & -4.5 & 0.19 \\
\hline $\mathrm{P} 4 \mathrm{c}$-decline to $\mathrm{AI}^{5}(\mathrm{~d})$ & 4,352 & $1.9 \pm 0.6$ & 0.1 to 4.9 & -0.1 & 1.6 & 1.9 & 2.3 & - \\
\hline AI to onset of luteal phase ${ }^{6}(\mathrm{~d})$ & 4,348 & $10.1 \pm 3.6$ & 3.1 to 33.4 & 1.7 & 9.6 & 10.1 & 10.7 & 0.09 \\
\hline $\mathrm{P} 4 \mathrm{c}$ at early diestrus ${ }^{\frac{7}{7}}(\mathrm{ng} / \mathrm{mL})$ & 4,313 & $3.1 \pm 4.3$ & 0.1 to 24.9 & 2.7 & 0.7 & 1.5 & 3.5 & 0.07 \\
\hline $\mathrm{P} 4 \mathrm{c}$ at mid diestrus ${ }^{8}(\mathrm{ng} / \mathrm{mL})$ & 4,207 & $16.0 \pm 7.5$ & 0.1 to 28.0 & -0.6 & 10.9 & 17.4 & 22.2 & 0.19 \\
\hline $\mathrm{P} 4 \mathrm{c}$ at late diestrus ${ }^{9}(\mathrm{ng} / \mathrm{mL})$ & 3,623 & $20.7 \pm 5.9$ & 0.1 to 28.0 & -1.4 & 18.2 & 22.5 & 25.0 & 0.12 \\
\hline P4c slope to mid diestrus ${ }^{4}(\mathrm{ng} / \mathrm{mL})$ & 4,040 & $1.9 \pm 1.7$ & -4.7 to 8.7 & 0.3 & 0.8 & 2.0 & 2.7 & 0.07 \\
\hline P4c slope to late diestrus ${ }^{4}(\mathrm{ng} / \mathrm{mL})$ & 3,623 & $5.1 \pm 2.2$ & -4.2 to 10.0 & -0.7 & 3.7 & 5.4 & 6.7 & 0.16 \\
\hline
\end{tabular}

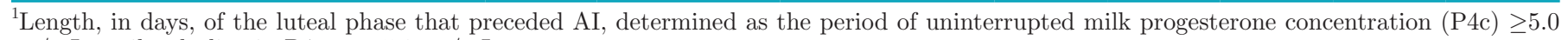
$\mathrm{ng} / \mathrm{mL}$ until a decline in $\mathrm{P} 4 \mathrm{c}$ to $<5.0 \mathrm{ng} / \mathrm{mL}$.

${ }^{2}$ Highest milk $\mathrm{P} 4 \mathrm{c}$ recorded in the last $8 \mathrm{~d}$ of the luteal phase that preceded AI.

${ }^{3} \mathrm{P} 4 \mathrm{c}$ at the day of first milk $\mathrm{P} 4 \mathrm{c}$ record $<5.0 \mathrm{ng} / \mathrm{mL}$ following cessation of the luteal phase that preceded AI.

${ }^{4}$ Average change in $\mathrm{P} 4 \mathrm{c}(\mathrm{ng} / \mathrm{mL})$ among the last 3 preceding $\mathrm{P} 4 \mathrm{c}$ records.

${ }^{5}$ Interval between cessation of the luteal phase (P4c-decline) and AI.

${ }^{6}$ Interval between AI and onset of subsequent luteal phase (first P4c $\geq 5.0 \mathrm{ng} / \mathrm{mL}$ post-AI).

${ }^{7} \mathrm{P} 4 \mathrm{c}$ record obtained at $6.1 \pm 1.1 \mathrm{~d}$ following $\mathrm{P} 4 \mathrm{c}$-decline and $4.5 \pm 0.6 \mathrm{~d}$ post-AI (range 3 to $6 \mathrm{~d}$ ).

${ }^{8} \mathrm{P} 4 \mathrm{c}$ record obtained at $13.6 \pm 2.4 \mathrm{~d}$ following $\mathrm{P} 4 \mathrm{c}$-decline and $10.0 \pm 0.6 \mathrm{~d}$ post-AI (range 7 to $11 \mathrm{~d}$ ).

${ }^{9} \mathrm{P} 4 \mathrm{c}$ record obtained at $16.8 \pm 2.1 \mathrm{~d}$ following $\mathrm{P} 4 \mathrm{c}$-decline and $14.1 \pm 0.6 \mathrm{~d}$ post-AI (range 12 to $15 \mathrm{~d}$ ).

${ }^{10}$ All repeatability estimates shown had $P<0.01$. 


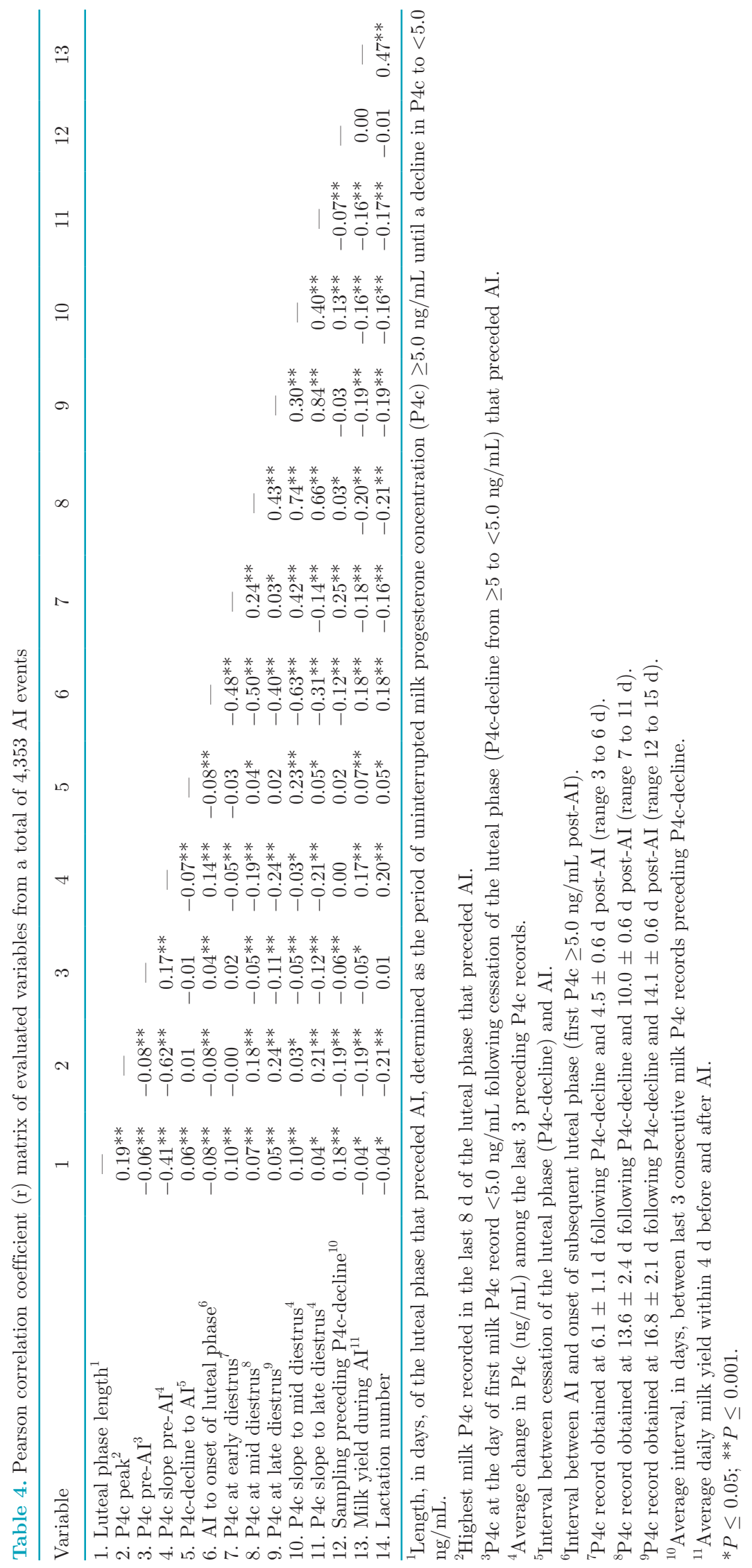


(a)
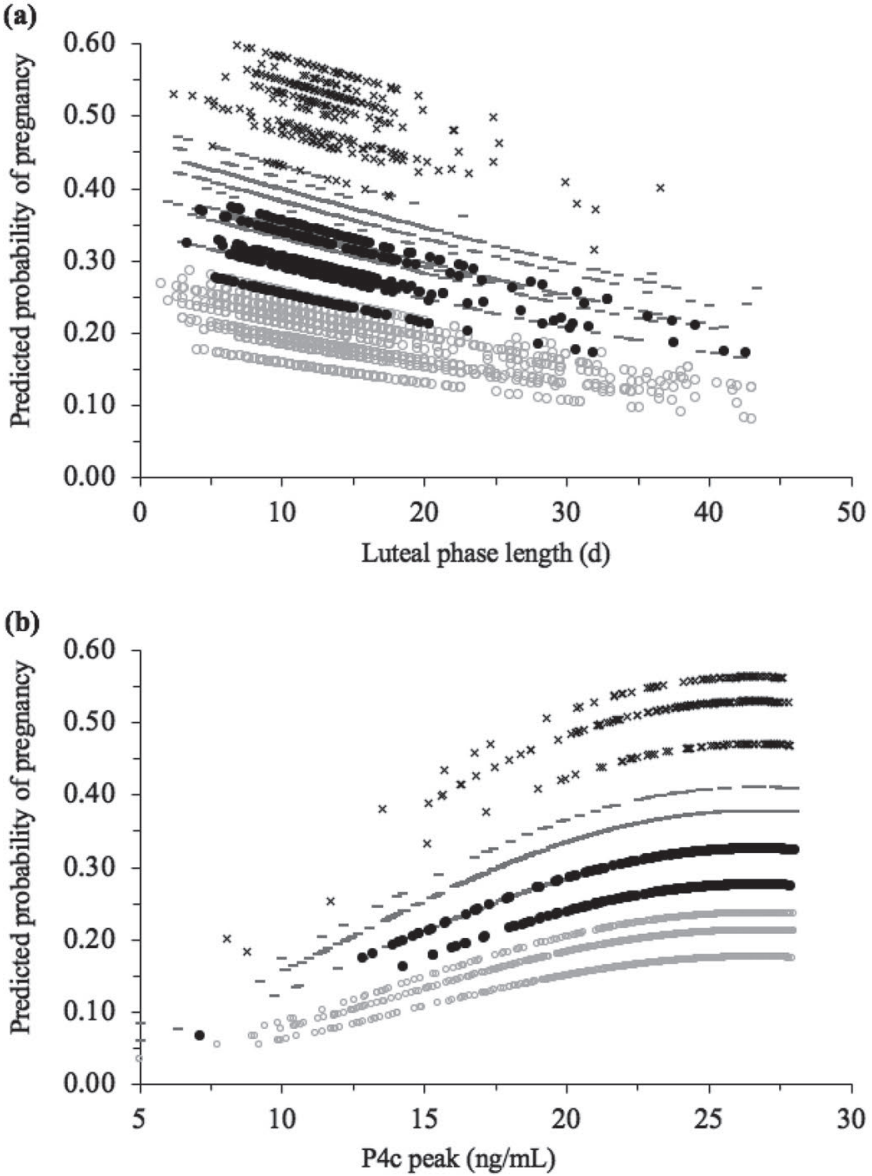

(c)

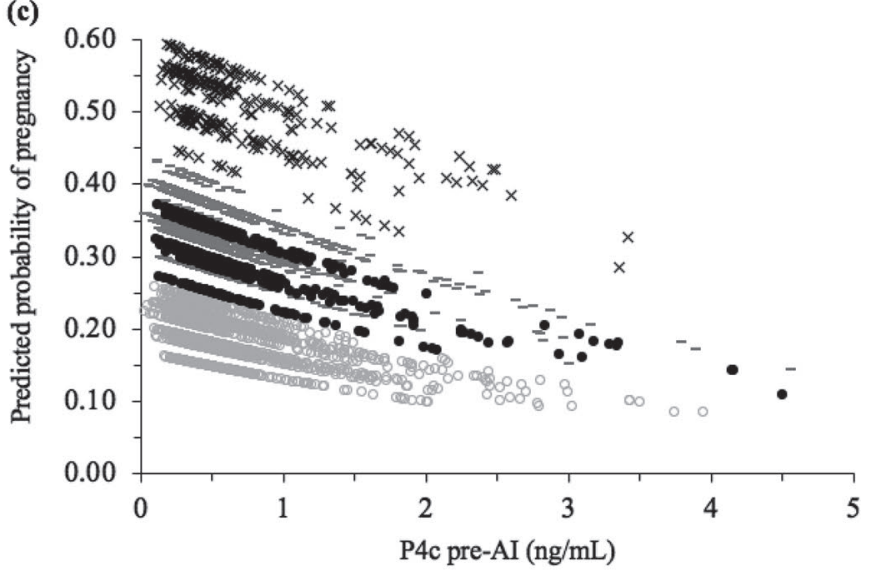

(d)

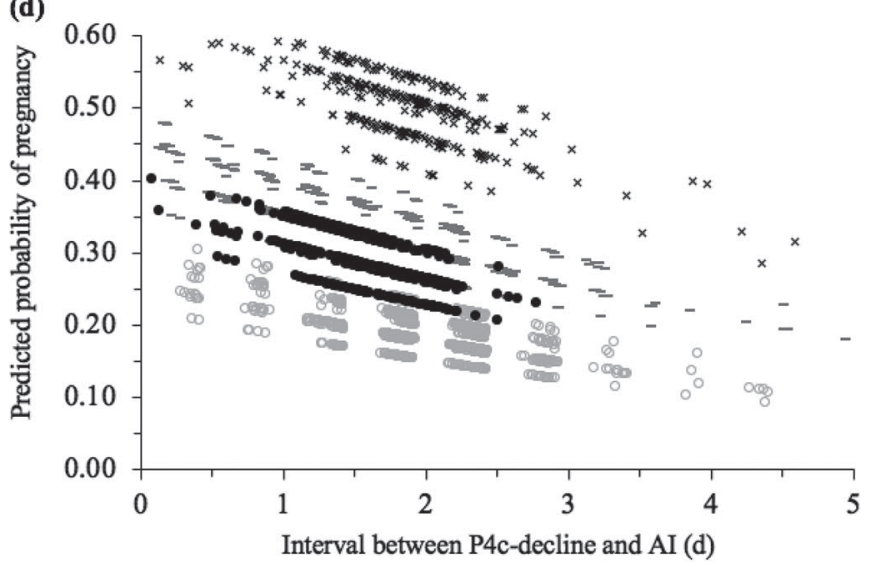

Figure 2. Estimated predicted probability of pregnancy of variables before AI obtained from the final mixed models: (a) luteal phase length $(P<0.001)$, defined as the number of days of uninterrupted progesterone concentration $(\mathrm{P} 4 \mathrm{c}) \geq 5.0 \mathrm{ng} / \mathrm{mL}$ until a decline to $<5.0 \mathrm{ng} / \mathrm{mL}$ that preceded AI; (b) P4c peak $(P=0.01)$, defined as the highest P4c recorded in the last $8 \mathrm{~d}$ of the luteal phase preceding an AI event; (c) P4c pre-AI $(P<0.001)$, defined as the $\mathrm{P} 4 \mathrm{c}$ at the time of $\mathrm{P} 4 \mathrm{c}$-decline, referred to as the first $\mathrm{P} 4 \mathrm{c}<5 \mathrm{ng} / \mathrm{mL}$ following a luteal phase and preceding AI; and $(d)$ interval between P4c-decline and AI $(P<0.001)$. For ease of interpretation, data points are identified by herd.

decreased $(P \leq 0.05)$ when $\mathrm{P} 4 \mathrm{c}$ peak was either $\leq 24.7$ $\mathrm{ng} / \mathrm{mL}$ (below the cut-point) or $\leq 22.7 \mathrm{ng} / \mathrm{mL}$ [quartile (Q) 1, mean $18.9 \mathrm{ng} / \mathrm{mL}$; Table 5].

A negative linear relationship $(P<0.001)$ between $\mathrm{P} 4 \mathrm{c}$ pre-AI and the probability of pregnancy was observed (Figure 2c), as well as a quadratic relationship $(P<0.001)$ between $\mathrm{P} 4 \mathrm{c}$ slope pre-AI and the probability of pregnancy (not shown). The ROC curve analysis revealed the largest combined Se and Sp $(P<$ 0.01 ) at $0.5 \mathrm{ng} / \mathrm{mL}$ (Se: 0.62, Sp: 0.44, AUC: 0.53$)$, and the probability of pregnancy was reduced $(P \leq 0.001)$ when $\mathrm{P} 4 \mathrm{c}$ pre-AI was $>0.5 \mathrm{ng} / \mathrm{mL}$ (above the cut-off) or $>0.7 \mathrm{ng} / \mathrm{mL}$ (Q4; mean $1.2 \mathrm{ng} / \mathrm{mL}$ ) compared with a $\mathrm{P} 4 \mathrm{c}$ pre-AI $\leq 0.5 \mathrm{ng} / \mathrm{mL}$ (Table 5 ).

Considering the above parameters of luteal activity before AI that were associated with improved probability of pregnancy, a total of $19.7 \%$ of $\mathrm{P} 4 \mathrm{c}$ profiles had a combination of luteal phase length $\leq 14.4 \mathrm{~d}, \mathrm{P} 4 \mathrm{c}$ peak $>24.7 \mathrm{ng} / \mathrm{mL}$, and $\mathrm{P} 4 \mathrm{c}$ pre-AI $\leq 0.5 \mathrm{ng} / \mathrm{mL}$. The predicted probability of pregnancy of such profiles was greater (41.5 vs. $31.1 \% ; P<0.001)$ than that of profiles that had luteal phase length $>14.4 \mathrm{~d}, \mathrm{P} 4 \mathrm{c}$ peak $\leq 24.7$ $\mathrm{ng} / \mathrm{mL}$, and $\mathrm{P} 4 \mathrm{c}$ pre-AI $>0.5 \mathrm{ng} / \mathrm{mL}$ (odds ratio: 1.57 , 95\% CI: 1.32 to 1.87$)$.

There was a negative linear relationship $(P<0.001)$ of interval between $\mathrm{P} 4 \mathrm{c}$-decline and AI with the probability of pregnancy (Figure 2d). For this variable, the largest combined Se and Sp to predict pregnancy $(P$ $<0.001$ ) was $1.6 \mathrm{~d}$ (Se: 0.37, Sp: 0.73, AUC: 0.57), and AI occurring beyond $1.6 \mathrm{~d}$ after P4c-decline resulted in reduced $(P=0.03)$ probability of pregnancy. Multiple comparisons among quartiles revealed reduced $(P<0.01)$ probability of pregnancy when the interval between P4c-decline and AI was $>2.3$ (Q4; mean 2.5 d) compared with $\leq 1.6 \mathrm{~d}$ (Q1; mean $1.1 \mathrm{~d}$; Table 5). A total of $7.2 \%$ of AI events occurred within $1 \mathrm{~d}$ after 
Table 5. Associations between variables before AI and the predicted probability of pregnancy at AI (P/AI) for a total of 4,353 AI events

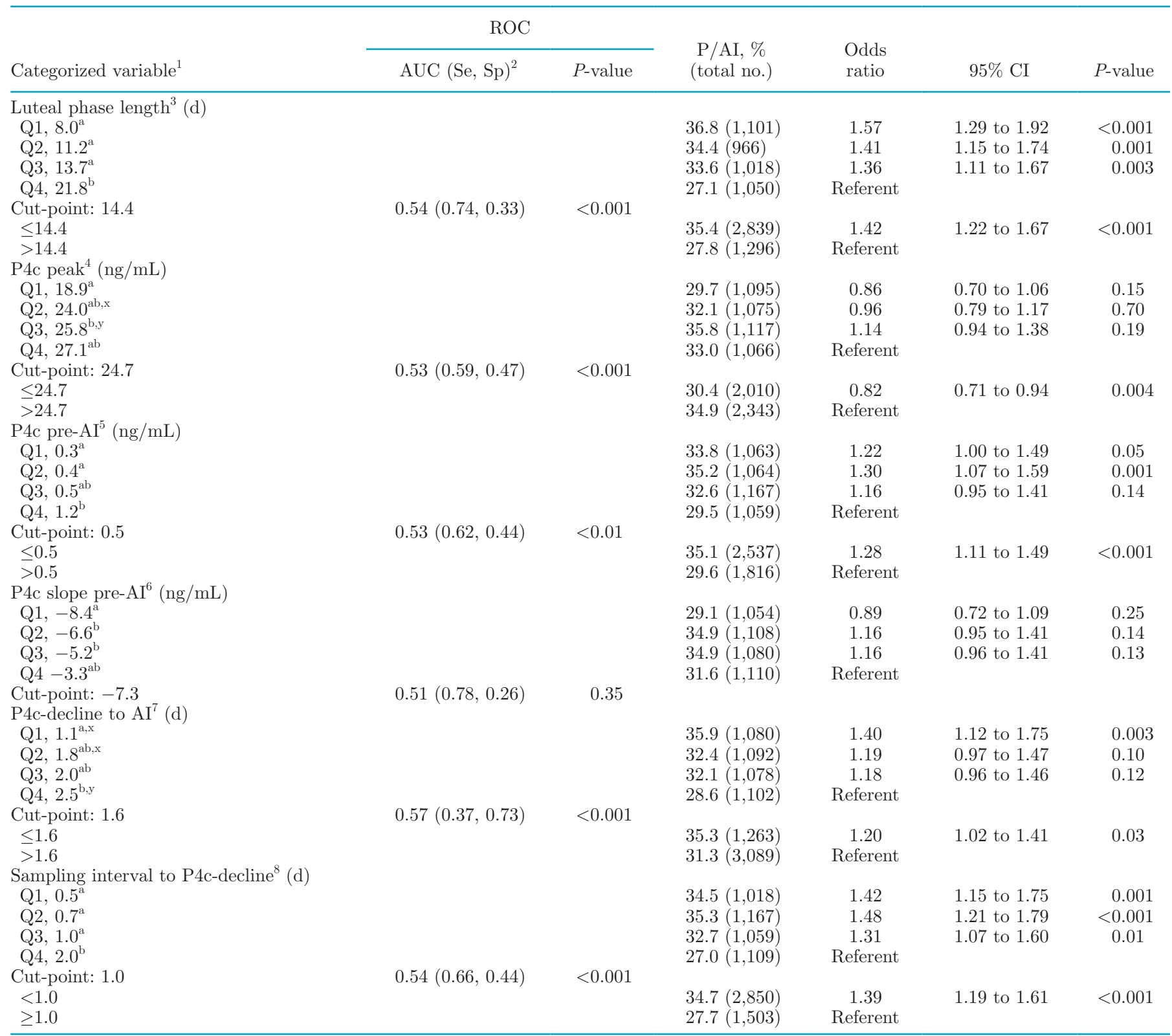

${ }^{\mathrm{a}-\mathrm{c}}$ Different superscripts denote differences $(P \leq 0.05)$ in $\mathrm{P} / \mathrm{AI}$ of multiple comparisons among quartiles of same variable.

${ }^{\mathrm{x}-\mathrm{z}}$ Different superscripts denote comparisons among quartiles of same variable tended $(P \leq 0.10)$ to differ in $\mathrm{P} / \mathrm{AI}$.

${ }^{1}$ Variables were categorized based on quartiles and receiver operating characteristic (ROC) curve analysis cut-points (below vs. above). Q1 = below 25th percentile; Q2 = between 25th and 50th percentiles; Q3 = between 50th and 75th percentiles; Q4 = above 75th percentile (Table 3). Mean value for each quartile is indicated.

${ }^{2}$ Area under the curve (AUC), sensitivity (Se), and specificity (Sp) respective to each cut-point obtained through ROC curve analysis that best predicted $(P \leq 0.05)$ pregnancy. Only variables that showed a significant ROC cut-point $(\mathrm{AUC} \geq 0.50$ and $P \leq 0.05)$ to predict the probability of pregnancy were compared among cut-point groups.

${ }^{3}$ Length of the luteal phase that preceded AI, determined as the period of uninterrupted milk progesterone concentration $(\mathrm{P} 4 \mathrm{c}) \geq 5.0 \mathrm{ng} / \mathrm{mL}$ until a decline in $\mathrm{P} 4 \mathrm{c}$ to $<5.0 \mathrm{ng} / \mathrm{mL}$.

${ }^{4}$ Highest progesterone concentration $(\mathrm{P} 4 \mathrm{c})$ recorded in the last $8 \mathrm{~d}$ of the luteal phase that preceded AI.

${ }^{5} \mathrm{P} 4 \mathrm{c}$ at the day of first milk $\mathrm{P} 4 \mathrm{c}$ record $<5.0 \mathrm{ng} / \mathrm{mL}$ following cessation of the luteal phase that preceded AI.

${ }^{6}$ Average change in $\mathrm{P} 4 \mathrm{c}(\mathrm{ng} / \mathrm{mL})$ among the last 3 preceding $\mathrm{P} 4 \mathrm{c}$ records.

${ }^{7}$ Interval between cessation of the luteal phase (P4c-decline) and $\mathrm{AI}$.

${ }^{8}$ Average interval between last 3 consecutive milk $\mathrm{P} 4 \mathrm{c}$ records preceding $\mathrm{P} 4 \mathrm{c}$-decline. 
P4c-decline, $87.1 \%$ occurred between 1.0 and $2.5 \mathrm{~d}$ after P4c-decline, and $5.7 \%$ occurred beyond $2.5 \mathrm{~d}$ after $\mathrm{P} 4 \mathrm{c}$-decline. The predicted probabilities of pregnancy were no different $(P=0.30)$ after an interval between $\mathrm{P} 4 \mathrm{c}$-decline and $\mathrm{AI}$ of $\leq 1.0$ versus an interval of 1.0 to 2.5 d (36.0 vs. $33.0 \%$; odds ratio: 1.14, $95 \%$ CI: 0.87 to 1.47). However, the predicted probability of pregnancy after an interval between P4c-decline and AI of 1.0 to $2.5 \mathrm{~d}$ was greater $(P<0.001)$ than an interval $>2.5 \mathrm{~d}$ (36.0 vs. $20.9 \%$; odds ratio: $1.87,95 \%$ CI: 1.32 to 2.65 ).

The ROC cut-point for the average interval, in days, among the last 3 milk $\mathrm{P} 4 \mathrm{c}$ records preceding $\mathrm{P} 4 \mathrm{c}-$ decline that best predicted pregnancy $(P<0.001)$ was 1.0 (Se: 0.66, Sp: 0.44, AUC: 0.54). The probability of pregnancy was decreased $(P<0.001)$ from 34.7 to $27.7 \%$ when the average sampling interval exceeded 1.0 d. Likewise, the probability of pregnancy was lower $(P$ $\leq 0.01)$ for Q4 (>1.3 d; mean $2.0 \mathrm{~d})$ compared with Q1, Q2, and Q3 ( $\leq 1.3 \mathrm{~d}$; Table 5).

\section{Variables After Al Associated with the Probability of Pregnancy}

Predicted probability curves of pregnancy for interval between AI and onset of luteal phase and for P4c at early, mid, and late diestrus are presented in Figure 3. There was a quadratic association $(P<0.001)$ of the interval between AI and onset of luteal phase with the probability of pregnancy (Figure 3a). The greatest $(P<0.001)$ probability of pregnancy $(36.3 \%)$ was observed when the onset of luteal phase (i.e., rise in $\mathrm{P} 4 \mathrm{c}$ to greater than or equal to $5.0 \mathrm{ng} / \mathrm{mL}$ ) occurred between 7 and $11 \mathrm{~d}$ post-AI, compared with an early (between 3 and $6 \mathrm{~d} ; 27.0 \%$ ) or delayed (beyond $12 \mathrm{~d}$; $24.2 \%$ ) onset of luteal phase post-AI (Table 6).

A quadratic association $(P<0.01)$ between $\mathrm{P} 4 \mathrm{c}$ at early diestrus and the probability of pregnancy was observed (Figure 3b). Multiple comparisons among quartiles showed that $\mathrm{P} 4 \mathrm{c}$ at early diestrus between 0.7 and $3.5 \mathrm{ng} / \mathrm{mL}(\mathrm{Q} 2$ and Q3) was associated $(P<$ $0.01)$ with increased probability of pregnancy compared with $\mathrm{P} 4 \mathrm{c} \leq 0.7$ (Q1) or $>3.5 \mathrm{ng} / \mathrm{mL}$ (Q4; Table 6). The $\mathrm{P} 4 \mathrm{c}$ at early diestrus was correlated $(P<0.001)$ with the interval between AI and onset of luteal phase $(\mathrm{r}=$ -0.48 ; Table 4).

A positive association $(P<0.001)$ was observed between $\mathrm{P} 4 \mathrm{c}$ at mid diestrus and the predicted probability of pregnancy (Figure 3c). The cut-point with the largest combined Se and Sp that predicted pregnancy $(P<0.001)$ was $12.4 \mathrm{ng} / \mathrm{mL}$, and the probability of pregnancy was reduced $(P<0.001)$ when $\mathrm{P} 4 \mathrm{c}$ at mid diestrus was below versus above the cut-point (23.6 vs. $36.1 \%$ ). Multiple comparisons among quartiles showed that the probability of pregnancy was reduced $(P<$
0.001 ) when $\mathrm{P} 4 \mathrm{c}$ was $\leq 10.9 \mathrm{ng} / \mathrm{mL}$ (Q1; mean $6.2 \mathrm{ng} /$ $\mathrm{mL}$ ) compared with $>10.9 \mathrm{ng} / \mathrm{mL}$. Nonetheless, either a low (Q1, mean $-0.2 \mathrm{ng} / \mathrm{mL}$ ) or a high (Q4, mean 3.8 $\mathrm{ng} / \mathrm{mL}) \mathrm{P} 4 \mathrm{c}$ slope to mid diestrus was associated $(P<$ 0.01 ) with reduced probability of pregnancy compared with a P4c slope to mid diestrus between 2.0 and 2.7 ng/mL (Q3, mean $2.4 \mathrm{ng} / \mathrm{mL}$; Table 6).

Positive linear relationships $(P<0.001)$ of $\mathrm{P} 4 \mathrm{c}$ at late diestrus (Figure 3d) and P4c slope to late diestrus (not shown) with the probability of pregnancy were observed. Significant ROC cut-points $(P<0.001)$ were determined for P4c at late diestrus (cut-point: $22.7 \mathrm{ng} /$ $\mathrm{mL}$, Se: 0.56, Sp: 0.54, AUC: 0.56) and for P4c slope to late diestrus (cut-point: $4.7 \mathrm{ng} / \mathrm{mL}$, Se: 0.71, Sp: 0.41, AUC: 0.58). Multiple comparisons among quartiles showed reduced probability of pregnancy for $\mathrm{P} 4 \mathrm{c}$ at late diestrus $<22.5 \mathrm{ng} / \mathrm{mL}(P \leq 0.03)$ and for $\mathrm{P} 4 \mathrm{c}$ slope to late diestrus $<6.7 \mathrm{ng} / \mathrm{mL}(P \leq 0.02$; Table 6$)$.

A total of $21.4 \%$ of $\mathrm{P} 4 \mathrm{c}$ profiles had a combination of interval between AI and onset of luteal phase between 7 and $11 \mathrm{~d}, \mathrm{P} 4 \mathrm{c}$ at early diestrus between 0.7 and 3.4 $\mathrm{ng} / \mathrm{mL}, \mathrm{P} 4 \mathrm{c}$ at mid diestrus $>12.4 \mathrm{ng} / \mathrm{mL}, \mathrm{P} 4 \mathrm{c}$ at late diestrus $>22.7 \mathrm{ng} / \mathrm{mL}, \mathrm{P} 4 \mathrm{c}$ slope to mid diestrus $>0.4$ $\mathrm{ng} / \mathrm{mL}$, and $\mathrm{P} 4 \mathrm{c}$ slope to late diestrus $>4.7 \mathrm{ng} / \mathrm{mL}$. The predicted probability of pregnancy of such "optimal" P4c profiles post-AI was greater ( 44.4 vs. $30.8 \%$; odds ratio: $1.80,95 \%$ CI: 1.50 to $2.16 ; P<0.001)$ than that of profiles that had interval between AI and onset of luteal phase $<7$ or $>11$ d, $\mathrm{P} 4 \mathrm{c}$ at early diestrus $<0.7$ or $>3.4 \mathrm{ng} / \mathrm{mL}, \mathrm{P} 4 \mathrm{c}$ at mid diestrus $\leq 12.4 \mathrm{ng} / \mathrm{mL}, \mathrm{P} 4 \mathrm{c}$ at late diestrus $<22.7 \mathrm{ng} / \mathrm{mL}, \mathrm{P} 4 \mathrm{c}$ slope to mid diestrus $\leq 0.4 \mathrm{ng} / \mathrm{mL}$, and $\mathrm{P} 4 \mathrm{c}$ slope to late diestrus $\leq 4.7 \mathrm{ng} /$ $\mathrm{mL}$.

The overall prevalence of categories determined based on quartiles or ROC cut-points that were associated with reduced $(P \leq 0.05)$ probability of pregnancy are presented in Figure 4. The most prevalent parameter was the interval between P4c-decline and AI $>1.6 \mathrm{~d}$, which occurred in $71.0 \%$ of $\mathrm{P} 4 \mathrm{c}$ profiles. After $\mathrm{AI}$, the most prevalent parameters were $\mathrm{P} 4 \mathrm{c}$ at late diestrus $\leq 22.7 \mathrm{ng} / \mathrm{mL}$ and $\mathrm{P} 4 \mathrm{c}$ slope to late diestrus $\leq 4.7 \mathrm{ng} /$ $\mathrm{mL}$, evident in 51.4 and $38.7 \%$ of the $\mathrm{P} 4 \mathrm{c}$ profiles evaluated, respectively.

\section{DISCUSSION}

\section{Characterization of In-Line Milk Progesterone Profiles}

The primary function of the IMAS biomodel is to estimate the day of estrus based on the decline in milk $\mathrm{P} 4 \mathrm{c}$, indicating the cessation of the luteal phase. The increased sampling frequency before P4c-decline observed indicates a relatively high precision of the biomodel in 
- Herd A $\circ$ Herd B $\bullet$ Herd C $\times$ Herd D
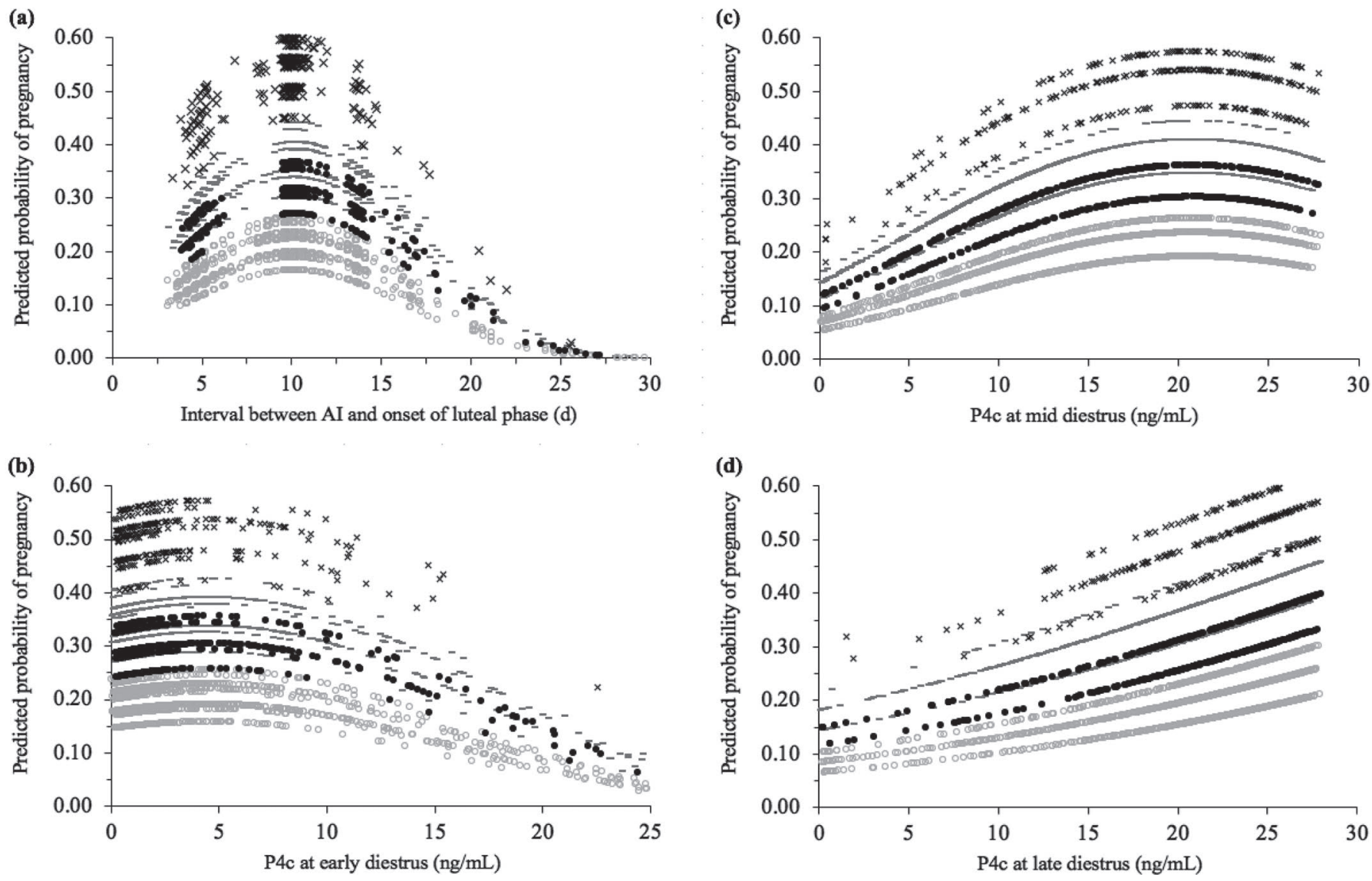

Figure 3. Estimated predicted probability of pregnancy of variables before AI obtained from the final mixed models: (a) interval between AI and onset of luteal phase $(P<0.001)$, defined as the interval, in days, between the day of AI and the first progesterone concentration $(\mathrm{P} 4 \mathrm{c})>5.0$ $\mathrm{ng} / \mathrm{mL}$ post-AI; (b) P4c at early diestrus $(P=0.003)$, defined as the $\mathrm{P} 4 \mathrm{c}$ record obtained at $4.5 \pm 0.6 \mathrm{~d}$ post-AI; (c) P4c at mid diestrus $(P<$ $0.001)$, defined as the $\mathrm{P} 4 \mathrm{c}$ record obtained at $10.0 \pm 0.6 \mathrm{~d}$ post-AI; and $(\mathrm{d}) \mathrm{P} 4 \mathrm{c}$ at late diestrus $(P<0.001)$, defined as $\mathrm{P} 4 \mathrm{c}$ record obtained at $14.1 \pm 0.6 \mathrm{~d}$ post-AI. For ease of interpretation, data points are identified by herd.

estimating the day of $\mathrm{P} 4 \mathrm{c}-$ decline. A reduced sampling frequency before P4c-decline was observed in a small proportion of the $\mathrm{P} 4 \mathrm{c}$ profiles evaluated, with only $10 \%$ of the profiles having an average interval of greater than $2 \mathrm{~d}$ between consecutive records before $\mathrm{P} 4 \mathrm{c}$-decline. In such cases, the increased interval between consecutive samples could have resulted in a reduced precision of estimating the day of P4c-decline and, consequently, subsequent variables. The final data set was based on filtering criteria applied to account for inconsistencies in the sampling frequency, as described elsewhere, that would have otherwise affected the precision of estimating the variables.

The day on which adjusted $\mathrm{P} 4 \mathrm{c}$ values declined to below the cut-off of $5.0 \mathrm{ng} / \mathrm{mL}$ was the IMAS standard reference point for monitoring $\mathrm{P} 4 \mathrm{c}$ profiles. Roelofs et al. (2006) reported that $5.0 \mathrm{ng} / \mathrm{mL}$ of milk P4c was comparable to a $2.0 \mathrm{ng} / \mathrm{mL}$ of plasma $\mathrm{P} 4 \mathrm{c}$ as cut-offs of decline in $\mathrm{P} 4 \mathrm{c}$ to anticipate time of ovulation, and the overall correlation between milk and plasma $\mathrm{P} 4 \mathrm{c}$ was high $(\mathrm{r}=0.62)$. In that study, the $5.0 \mathrm{ng} / \mathrm{mL}$ cut-off for milk $\mathrm{P} 4 \mathrm{c}$ resulted in less variation in the interval between decline in $\mathrm{P} 4 \mathrm{c}$ and ovulation when compared with either a higher $(15.0 \mathrm{ng} / \mathrm{mL})$ or lower $(2.0 \mathrm{ng} /$ mL) cut-off (Roelofs et al., 2006). Nonetheless, the IMAS cut-off used in this data set seemed to have estimated the cessation of luteal phase with reasonably high precision, as the actual $\mathrm{P} 4 \mathrm{c}$ at $\mathrm{P} 4 \mathrm{c}$-decline (i.e., $\mathrm{P} 4 \mathrm{c}$ pre-AI) averaged $0.6 \pm 0.5 \mathrm{ng} / \mathrm{mL}$, with $95 \%$ of the observations being less than or equal to $1.5 \mathrm{ng} /$ $\mathrm{mL}$. Furthermore, the $\mathrm{P} 4 \mathrm{c}$ change among the last $3 \mathrm{P} 4 \mathrm{c}$ records that preceded $\mathrm{P} 4 \mathrm{c}$-decline (i.e., slope pre-AI) averaged $-5.9 \pm 2.0 \mathrm{ng} / \mathrm{mL}$ (Table 3 ).

The luteal phase length (mean $\pm \mathrm{SD}$ ) preceding AI was $13.7 \pm 6.2 \mathrm{~d}$, similar to previous reports of 12.9 \pm 5.0 (Lamming and Darwash, 1998) and $13.0 \pm 11.5$ 
d (Tenghe et al., 2015). The inter-luteal phase length averaged $12.0 \pm 3.7 \mathrm{~d}$ and was greater than the $7.8 \pm$ 4.3 and $9.3 \pm 8.5 \mathrm{~d}$ reported by Lamming and Darwash (1998) and Tenghe et al. (2015), respectively. Repeat- ability estimates for luteal and inter-luteal lengths were 0.16 and 0.09 , respectively, which were greater than that of Tenghe et al. (2015), who reported estimates close to zero for both variables. The variation in inter-

Table 6. Associations between variables after AI and the predicted probability of pregnancy at AI (P/AI) for a total of 4,353 AI events

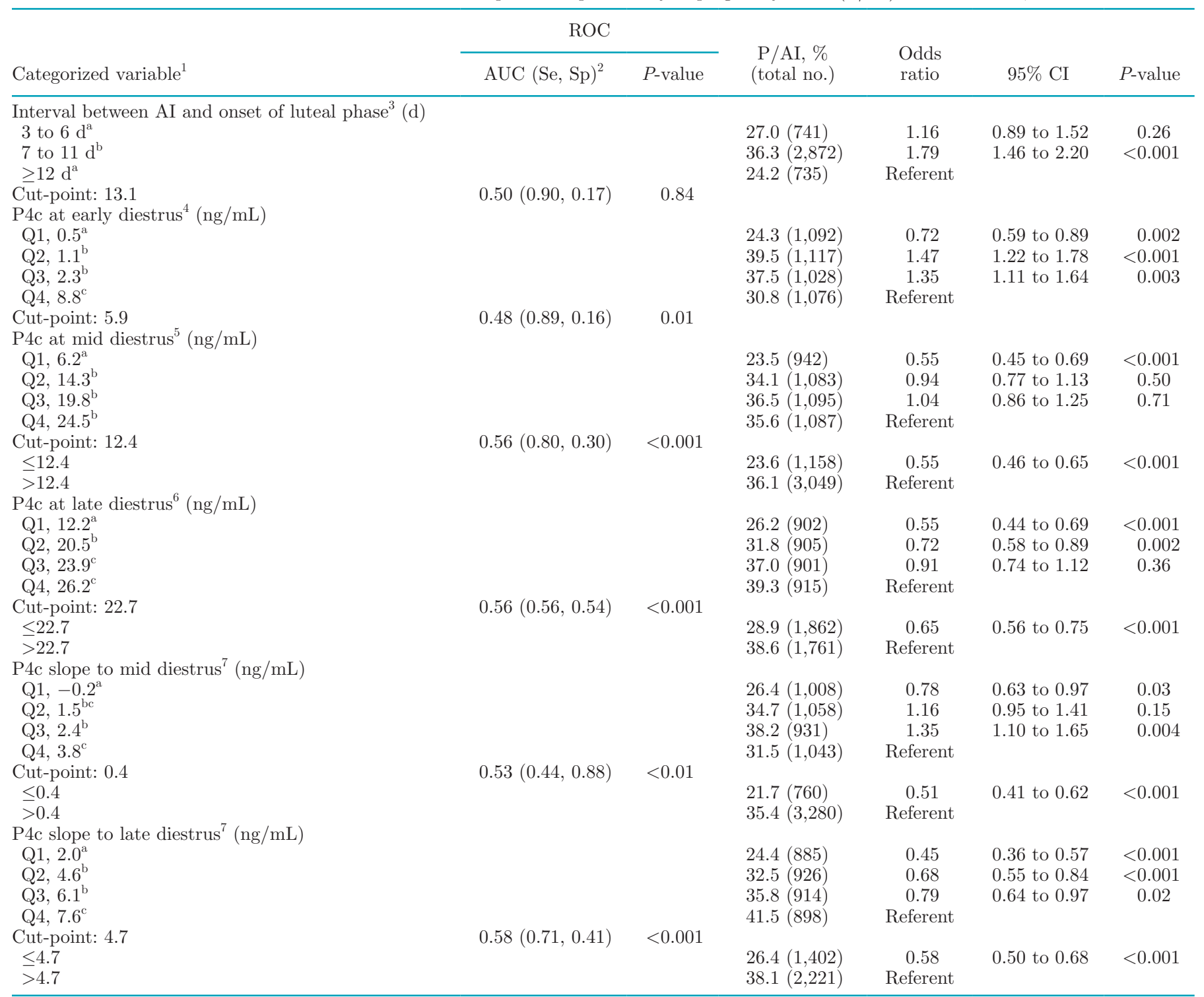

${ }^{\mathrm{a}-\mathrm{c}}$ Different superscripts denote differences $(P \leq 0.05)$ in $\mathrm{P} / \mathrm{AI}$ of multiple comparisons among quartile of same variable.

${ }^{1}$ Variables were categorized based on quartiles and receiver operating characteristic (ROC) curve analysis cut-points (below vs. above). Q1 $=$ below 25th percentile; Q2 = between 25th and 50th percentiles; Q3 = between 50th and 75th percentiles; Q4 = above 75th percentile (Table 3). Mean value for each quartile is indicated.

${ }^{2}$ Area under the curve (AUC), sensitivity (Se), and specificity (Sp) respective to the cut-point obtained through ROC curve analysis that best predicted $(P \leq 0.05)$ pregnancy. Only variables that showed a significant ROC cut-point $(\mathrm{AUC} \geq 0.50$ and $P \leq 0.05)$ to predict the probability of pregnancy were compared among cut-point groups.

${ }^{3}$ Interval between $\mathrm{AI}$ and onset of subsequent luteal phase [first progesterone concentration $(\mathrm{P} 4 \mathrm{c}) \geq 5.0 \mathrm{ng} / \mathrm{mL}$ post-AI], categorized as occurring between 3 and $6 \mathrm{~d}$ post-AI, between 7 and $11 \mathrm{~d}$ post-AI, or beyond $12 \mathrm{~d}$ post-AI.

${ }^{4} \mathrm{P} 4 \mathrm{c}$ record obtained at $6.1 \pm 1.1 \mathrm{~d}$ following $\mathrm{P} 4 \mathrm{c}$-decline and $4.5 \pm 0.6 \mathrm{~d}$ post-AI (range 3 to $6 \mathrm{~d}$ ).

${ }^{5} \mathrm{P} 4 \mathrm{c}$ record obtained at $13.6 \pm 2.4 \mathrm{~d}$ following $\mathrm{P} 4 \mathrm{c}$-decline and $10.0 \pm 0.6 \mathrm{~d}$ post-AI (range 7 to $11 \mathrm{~d}$ ).

${ }^{6} \mathrm{P} 4 \mathrm{c}$ record obtained at $16.8 \pm 2.1 \mathrm{~d}$ following $\mathrm{P} 4 \mathrm{c}$-decline and $14.1 \pm 0.6 \mathrm{~d}$ post-AI (range 12 to $15 \mathrm{~d}$ ).

${ }^{7}$ Average change in $\mathrm{P} 4 \mathrm{c}(\mathrm{ng} / \mathrm{mL})$ among the last three preceding $\mathrm{P} 4 \mathrm{c}$ records. 
luteal phase lengths among studies might be explained by the different sampling frequency during P4c profiles and, consequently, different criteria in estimating this variable. In the present study, the greater inter-luteal phase length might have occurred because of the reduced sampling frequency during inter-luteal phases.

The inter-luteal phase length determined based on milk $\mathrm{P} 4 \mathrm{c}$ profiles alone was longer than expected when considering the actual interval between luteolysis and ovulation. For instance, the interval between decline in either milk or plasma $\mathrm{P} 4 \mathrm{c}$ and confirmation of ovulation using transrectal ultrasonography averaged 3 (Roelofs et al., 2006) to 5 d (Sartori et al., 2004), whereas the average inter-luteal phase length in the present study was $12 \mathrm{~d}$. This suggests that the increase in milk $\mathrm{P} 4 \mathrm{c}$ indicative of luteal activity occurs much later, at least $7 \mathrm{~d}$ after ovulation. However, such an assumption does not consider cows that could have had a delayed ovulation, which would result in increased inter-luteal phase length, as demonstrated by Sartori et al. (2004). Consequently, the late increase in milk $\mathrm{P} 4 \mathrm{c}$ in relation to day of ovulation would explain the overall short luteal phase length observed in studies evaluating milk P4c profiles (Lamming and Darwash, 1998; Tenghe et al., 2015), when compared with the expected corpus luteum (CL) lifespan of approximately 18 d (Sartori et al., 2004).

The P4c obtained at early diestrus averaged $3.1 \pm 4.3$ $\mathrm{ng} / \mathrm{mL}$ and was similar to the milk P4c values reported by Stronge et al. (2005) at $4 \mathrm{~d}$ post-AI. In the present study, P4c increased to $16.0 \pm 7.5$ and to $20.7 \pm 5.9$ $\mathrm{ng} / \mathrm{mL}$ at mid diestrus and late diestrus, respectively. The P4c at early, mid, and late diestrus were determined by single $\mathrm{P} 4 \mathrm{c}$ record available at each time point (at $4.5 \pm 0.6,10.0 \pm 0.6$ and $14.1 \pm 0.6 \mathrm{~d}$ post-AI, respectively), which varied considerably, particularly at early diestrus. Such variations in milk P4c could be attributed to components that were not evaluated here, such as milk fat (Pope et al., 1976), although Stronge et al. (2005) found no associations between milk components (fat, protein, lactose) and milk P4c at 4 to $7 \mathrm{~d}$ post-AI. The determination of $\mathrm{P} 4 \mathrm{c}$ peak in the present study was based on the highest $\mathrm{P} 4 \mathrm{c}$ obtained during the $8 \mathrm{~d}$ that preceded $\mathrm{P} 4 \mathrm{c}$-decline, when $5.6 \pm 2.1 \mathrm{P} 4 \mathrm{c}$ records were available, on average. This likely reduced potential variations in $\mathrm{P} 4 \mathrm{c}$ that could be attributed to components not assessed here (such as milk fat) if only a single $\mathrm{P} 4 \mathrm{c}$ record had been used to determine $\mathrm{P} 4 \mathrm{c}$ peak. The $\mathrm{P} 4 \mathrm{c}$ peak averaged $24.0 \pm 3.6 \mathrm{ng} / \mathrm{mL}$ and was similar to previous reports evaluating milk P4c in dairy cows (Pope et al., 1976; Roelofs et al., 2006; Bruinjé et al., 2017b).

The average cycle length was $25.6 \pm 6.6 \mathrm{~d}$, with a repeatability estimate of $0.12(P<0.01)$. Similarly, Tenghe et al. (2015) reported a cycle length of 26.2 $\pm 13.3 \mathrm{~d}$ based on P4c profiles obtained by the same IMAS, but with no significant repeatability estimate. Although these data are based on $\mathrm{P} 4 \mathrm{c}$ profiles alone, they indicate a greater variability in the estrous cycle length over the general assumption of 18 to $24 \mathrm{~d}$ in length (Savio et al., 1990). Such greater variation in the estrous cycle length could be associated with increased

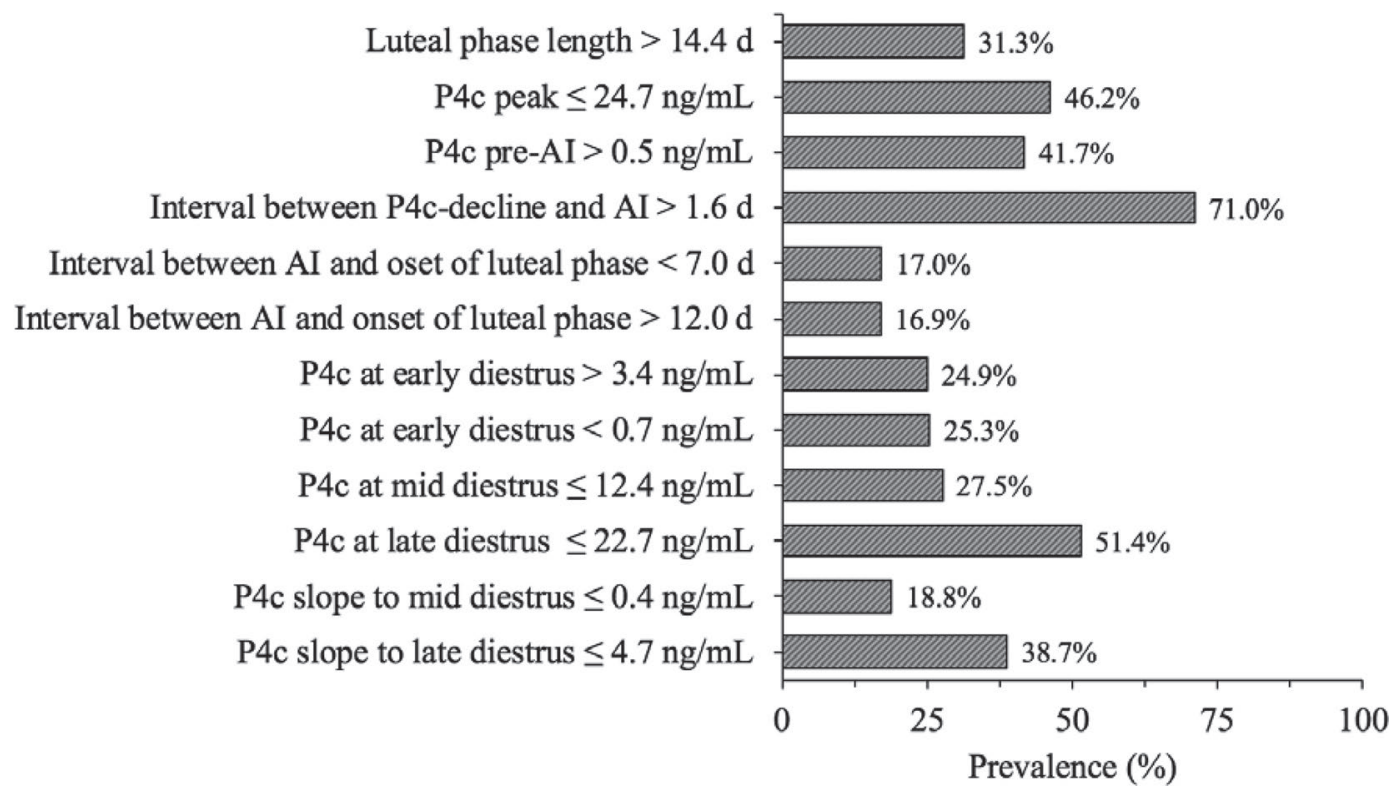

Figure 4. Prevalence $(\%)$ of parameters of luteal activity associated $(P \leq 0.05)$ with reduced probability of pregnancy among the progesterone concentration $(\mathrm{P} 4 \mathrm{c})$ profiles evaluated, as indicated in Tables 4 and 5 . 
incidence of delayed ovulations (Lamming and Darwash, 1998; Sartori et al., 2004) and the unexpectedly large variations reported in the inter-service interval (Remnant et al., 2015, 2016).

\section{Variables Before Al Associated with the Probability of Pregnancy}

Evaluations of luteal phase length in previous studies were often based on pre-determined classifications (Opsomer et al., 1998; Ranasinghe et al., 2011) or based on the general assumption that the bovine estrous cycle length ranges from 18 to $24 \mathrm{~d}$ (Savio et al., 1990). This latter assumption often resulted in estimates of high prevalence (of approximately 50\%) of abnormal cycle length in postpartum dairy cows (Opsomer et al., 1998; Hommeida et al., 2004). Although the cut-point of 14.4 $\mathrm{d}$ of luteal phase length obtained through ROC analysis in the present study had low accuracy to predict the outcome of AI, it can be used as a reference point to identify prolonged luteal phases in herds monitoring $\mathrm{P} 4 \mathrm{c}$ profiles that reduce the probability of pregnancy.

Factors reported to be associated with increased luteal phase length, such as delayed resumption of estrous cyclicity postpartum and postpartum uterine disorders (Ranasinghe et al., 2011), were also associated with reduced fertility (Ranasinghe et al., 2011; Bruinjé et al., 2017a). It is possible that a prolonged luteal phase indicates an impaired or delayed spontaneous luteolysis that could be associated with health complications that were not evaluated here. For instance, Ranasinghe et al. (2011) reported that cows undergoing postpartum uterine complications arising from dystocia, retention of fetal membranes, or conditions such as endometritis, metritis, or pyometra were 5 times more likely to have a prolonged luteal phase (greater than $20 \mathrm{~d}$ in length). Another possibility is that a prolonged luteal phase might interfere with the biomodel's precision to detect the day of P4c-decline. Beyond a certain day of the cycle (i.e., $25 \mathrm{~d}$ after the previous $\mathrm{P} 4 \mathrm{c}$-decline), the sampling frequency is decreased. If the cessation of a prolonged luteal phase occurs during a period with reduced sampling frequency, the day of $\mathrm{P} 4 \mathrm{c}$-decline would be determined with reduced precision, resulting in less precise timing of AI and consequently reduced probability of pregnancy.

The importance of increased $\mathrm{P} 4 \mathrm{c}$ during the development of the ovulatory follicle and its positive association with fertility has been studied. In this regard, Bisinotto et al. (2013) reported that cows having increased plasma $\mathrm{P} 4 \mathrm{c}$ from 7 to $3 \mathrm{~d}$ preceding timed-AI either by the presence of a CL $(3.4 \mathrm{ng} / \mathrm{mL})$ or via exogenous $\mathrm{P} 4$ $(2.7 \mathrm{ng} / \mathrm{mL})$ had greater pregnancy per AI compared with cows with low plasma $\mathrm{P} 4 \mathrm{c}(0.5 \mathrm{ng} / \mathrm{mL})$ during that period. In the present study, we only evaluated cows that had a luteal phase before AI and that had increased sampling frequency during the last $8 \mathrm{~d}$ of the luteal phase, to characterize to what extent the $\mathrm{P} 4 \mathrm{c}$ peak during the luteal phase preceding AI could be associated with fertility.

We observed that $46.2 \%$ of the luteal phases had a $\mathrm{P} 4 \mathrm{c}$ peak $\leq 24.7 \mathrm{ng} / \mathrm{mL}$ before AI, which was associated with decreased probability of pregnancy. Although this suggests that increased $\mathrm{P} 4 \mathrm{c}$ in the cycle preceding AI might increase fertility, Bisinotto et al. (2015) evaluated cows that had a CL before AI and did not find improvement in fertility when plasma $\mathrm{P} 4 \mathrm{c}$ was increased ( 7.4 vs. $6.2 \mathrm{ng} / \mathrm{mL}$ ) from 9 to $3 \mathrm{~d}$ preceding timed-AI through additional supplemental P4. Although the latter study evaluated $\mathrm{P} 4 \mathrm{c}$ in plasma rather than in milk, the correlation between P4c in plasma and milk is high (Pope et al., 1976; Roelofs et al., 2006), and intravaginal $\mathrm{P} 4$ supplementation increases $\mathrm{P} 4 \mathrm{c}$ in both plasma and milk (van Cleeff et al., 1992). Similarly, Colazo et al. (2013) reported no improvements in fertility in pre-synchronized cows that received supplemental $\mathrm{P} 4$ during the synchronization protocol preceding AI compared with cows that were subjected to the same protocol but not supplemented with $\mathrm{P} 4$. These studies (Colazo et al., 2013; Bisinotto et al., 2015) suggest that P4 supplementation does not affect fertility in cows with high $\mathrm{P} 4 \mathrm{c}$ in the cycle preceding AI.

It is possible that lower $\mathrm{P} 4 \mathrm{c}$ peak during the luteal phase preceding AI might have caused altered luteolytic signal resulting in premature luteolysis in the subsequent luteal phase post-AI, as previously reported (Cerri et al., 2011), reducing the probability of pregnancy. In this regard, we observed a positive, but weak relationship $(P<0.001)$ between $\mathrm{P} 4 \mathrm{c}$ peak and luteal phase length $(\mathrm{r}=0.19$; Table 4$)$.

All AI events evaluated herein were preceded by a P4c-decline below $5.0 \mathrm{ng} / \mathrm{mL}$, which indicated a spontaneous cessation of the previous luteal phase. Regardless, elevated P4c pre-AI ( $>0.5 \mathrm{ng} / \mathrm{mL})$ was associated with reduced probability of pregnancy. Reasons for elevated P4c following a spontaneous cessation of luteal phase is unclear; however, it is possible that an incomplete luteolysis would drop the P4c below the cut-off value of $5.0 \mathrm{ng} / \mathrm{mL}$ yet maintain a slightly high $\mathrm{P} 4 \mathrm{c}$ around the time of AI. Previous reports demonstrated that more than $20 \%$ of cows might experience an incomplete or inadequate luteolysis during GnRH-based synchronization protocols (Wiltbank et al., 2012), which might cause elevated circulating $\mathrm{P} 4 \mathrm{c}$ near time of $\mathrm{AI}$ and consequently reduced fertility (Ambrose et al., 2015; Colazo et al., 2017). The above studies were based on cows subjected to synchronization treatments; therefore, investigating the actual incidence of incom- 
plete luteolysis in spontaneously cycling cows is warranted. However, based on our results that $41.7 \%$ of AI were preceded by $\mathrm{P} 4 \mathrm{c}$ pre-AI $>0.5 \mathrm{ng} / \mathrm{mL}$ (Figure 4 ) and associated with reduced probability of pregnancy (Table 5), we speculate that incomplete luteolysis could be at least partially contributing to such association. Another potential contributing factor to elevated P4c pre-AI being negatively associated with the probability of pregnancy is the biomodel sampling frequency. The sampling frequency before $\mathrm{P} 4 \mathrm{c}$-decline was, on average, increased to daily samples (Table 2). However, $10 \%$ of the profiles had a sampling interval greater than $2 \mathrm{~d}$ between consecutive samples before P4c-decline, which could have contributed to an inaccurate (i.e., late) determination of the day of $\mathrm{P} 4 \mathrm{c}$-decline. This could result in cows having elevated $\mathrm{P} 4 \mathrm{c}$ pre-AI, and $\mathrm{AI}$ occurring after ovulation. We evaluated the overall association between the sampling interval preceding P4c-decline and the $\mathrm{P} 4 \mathrm{c}$ pre-AI, which turned out to be very weak $(\mathrm{r}=-0.06, P<0.001)$. Further research is required to examine the prevalence of incomplete luteolysis based on the current IMAS biomodel, and to re-examine the standard $5.0 \mathrm{ng} / \mathrm{mL}$ cut-off to detect cessation of the luteal phase, as proposed by Adriaens et al. (2018). Increasing the sampling frequency toward the end of the luteal phase until the time of AI is likely to improve the precision of AI.

Studies have evaluated the optimal time of AI in relation to onset of estrus based on mounting or stepping activity (Dransfield et al., 1998; Stevenson et al., 2014) or in relation to expected ovulation time in cows subjected to synchronized ovulation (Pursley et al., 1998). However, the optimal interval between $\mathrm{P} 4 \mathrm{c}$-decline and $\mathrm{AI}$ is yet to be determined to maximize AI success in herds monitoring in-line $\mathrm{P} 4 \mathrm{c}$ profiles. Bleach et al. (2004) reported an interval of approximately $3 \mathrm{~d}$ from spontaneous luteolysis (detected by ultrasonography) to estrus, and Roelofs et al. (2006) reported an interval of approximately $80 \mathrm{~h}$ between spontaneous decline in milk P4c to less than $5.0 \mathrm{ng} / \mathrm{mL}$ and ovulation, with a high variability (range 54 to $98 \mathrm{~h}$ ) among cows.

The manufacturer's recommendation for herds using the IMAS is to inseminate cows between 24 and $36 \mathrm{~h}$ (i.e., 1.0 to $1.5 \mathrm{~d}$ ) after a P4c-decline (DeLaval International, 2011). In the present study, the interval between P4c-decline and AI greater than $1.6 \mathrm{~d}$ resulted in reduced probability of pregnancy. It is noteworthy that the present study did not aim to test different intervals between $\mathrm{P} 4 \mathrm{c}$-decline and $\mathrm{AI}$, and the exact time of which AI was performed was not available. Besides, the variability in the interval between $\mathrm{P} 4 \mathrm{c}$-decline and AI was small, and $87.1 \%$ of the AI events evaluated occurred between 1.0 and $2.5 \mathrm{~d}$ after P4c-decline.
Therefore, a short or long interval between P4c-decline and AI and its association with the probability of pregnancy should be cautiously interpreted. Interestingly, however, the predicted probabilities of pregnancy were not different $(P=0.30)$ whether the interval between P4c-decline and AI was $\leq 1.0$ or between 1.0 and $2.5 \mathrm{~d}$ (36.0 vs. $33.0 \%)$.

The probability of pregnancy was decreased from 34.7 to $27.7 \%$ when the average sampling interval before P4c-decline exceeded $1.0 \mathrm{~d}$. This suggests that less frequent sampling at the end of the luteal phase may be determining the day of $\mathrm{P} 4 \mathrm{c}$-decline later than the actual day of luteolysis. As previously discussed, this could happen if a prolonged luteal phase occurs, as the sampling frequency is reduced beyond the expected cessation of the luteal phase (i.e., beyond approximately $23 \mathrm{~d}$ after AI). We observed a positive association ( $P$ $<0.001$ ) between luteal phase length and sampling interval preceding $\mathrm{P} 4 \mathrm{c}$-decline $(\mathrm{r}=0.18$; Table 4$)$, meaning that a reduced sampling frequency in cows with prolonged luteal phase could contribute to reduced precision of timing of AI, consequently affecting the probability of pregnancy.

\section{Variables After Al Associated with the Probability of Pregnancy}

Increasing circulating $\mathrm{P} 4 \mathrm{c}$ following $\mathrm{AI}$ is essential to prepare the uterine environment and nurture embryo development (Garrett et al., 1988); thus, lower $\mathrm{P} 4 \mathrm{c}$ during mid and late diestrus were expected to be associated with reduced fertility. In the present study, a quadratic association of the interval between $\mathrm{AI}$ and onset of luteal phase with the probability of pregnancy was observed (Figure 3a). A previous study reported a negative relationship of milk $\mathrm{P} 4 \mathrm{c}$ at $4 \mathrm{~d}$ post-AI with embryo survival, but a positive relationship of $\mathrm{P} 4 \mathrm{c}$ at 5 , 6 , and $7 \mathrm{~d}$ post-AI with embryo survival (Stronge et al., 2005). Comparisons between rise in P4c occurring at 4, 5,6 , and $7 \mathrm{~d}$ post-AI and the probability of pregnancy were not possible here, as sampling frequency was automatically reduced during the early post-AI period. $\mathrm{A}$ rapid increase in $\mathrm{P} 4 \mathrm{c}$ post-AI, which could happen when AI is delayed, would lower the chances of fertilization (Valenza et al., 2012) and result in increased P4c early post-AI. Another possibility is the occurrence of an incomplete luteolysis preceding AI, which could reduce $\mathrm{P} 4 \mathrm{c}$ to less than $5.0 \mathrm{ng} / \mathrm{mL}$ (indicating a $\mathrm{P} 4 \mathrm{c}$-decline), yet result in elevated $\mathrm{P} 4 \mathrm{c}$ near time of $\mathrm{AI}$ (e.g., pre-AI), and consequently a rapid increase in $\mathrm{P} 4 \mathrm{c}$ early post-AI. A very weak association $(\mathrm{r}=0.04, P=$ 0.001 ) between $\mathrm{P} 4 \mathrm{c}$ pre-AI and interval between $\mathrm{AI}$ and onset of luteal phase was observed in the present study, 
possibly due to the high variability among $\mathrm{P} 4 \mathrm{c}$ profiles for both variables.

Lamming and Darwash (1998) analyzed milk P4c profiles in over 1,600 dairy cows and reported that $12.9 \%$ of cycles had a delayed onset of luteal phase, which was defined as an inter-luteal phase greater than or equal to $12 \mathrm{~d}$ long. We found a similar prevalence (16.9\%) of delayed onset of luteal phase, which was negatively associated with the probability of pregnancy (Figure 3a; Table 6). A delayed onset of luteal phase post-AI will result in lower $\mathrm{P} 4 \mathrm{c}$ at early diestrus, whereas a short interval between $\mathrm{AI}$ and onset of luteal phase might result in greater $\mathrm{P} 4 \mathrm{c}$ at early diestrus (i.e., between 3 and $6 \mathrm{~d}$ post-AI). Both factors were associated with reduced probability of pregnancy. Lower $\mathrm{P} 4 \mathrm{c}$ at early diestrus could be associated with the accelerated hepatic clearance rate of $\mathrm{P} 4$ reported in high-producing dairy cows (Sangsritavong et al., 2002), as a negative relationship between milk yield during the time of AI and milk P4c at $4 \mathrm{~d}$ post-AI was also reported (Stronge et al., 2005). In the present study, milk yield during AI was negatively associated with $\mathrm{P} 4 \mathrm{c}$ at early $(\mathrm{r}=$ $-0.18)$, mid $(\mathrm{r}=-0.20)$, and late diestrus $(\mathrm{r}=-0.19$; Table 4).

\section{Prevalence of Parameters Associated with Reduced Fertility and Potential Strategies to Improve Fertility}

Most variables of luteal activity evaluated in the present study had significant associations with the probability of pregnancy. The cut-points obtained by ROC curve analysis had low accuracy to predict pregnancy. Nonetheless, they were used as reference points to categorize parameters negatively associated with fertility, which were often highly prevalent (Figure 4). Based on the reference points that resulted in increased probability of pregnancy, only $5.6 \%(182 / 3,234)$ of $\mathrm{P} 4 \mathrm{c}$ profiles had a combination of "optimal" luteal activity parameters (i.e., within categories that were associated with improved probability of pregnancy) both before and after AI. The predicted probability of pregnancy for such P4c profiles was greater (52.2 vs. $33.3 \%$; $P<$ 0.001 ) than that of $\mathrm{P} 4 \mathrm{c}$ profiles that had a combination of categories associated with reduced probability of pregnancy. However, inferences from such a comparison should be drawn cautiously due to the limited number of $\mathrm{P} 4 \mathrm{c}$ profiles with the so called "optimal" parameters both before and after AI.

In total, $31.3 \%$ of the evaluated $\mathrm{P} 4 \mathrm{c}$ profiles had a prolonged luteal phase $(>14.4 \mathrm{~d})$, and $46.2 \%$ had a P4c peak $\leq 24.7 \mathrm{ng} / \mathrm{mL}$, both factors negatively associated with the probability of pregnancy. Evaluating specific mechanisms of these parameters affecting the probabil- ity of pregnancy was outside the scope of the present study. However, it can be hypothesized that inducing CL regression through administration of exogenous $\mathrm{PGF}_{2 \alpha}$ (Pursley et al., 1995) in cows that were not inseminated in the antecedent cycle but had a luteal phase exceeding $14.4 \mathrm{~d}$ in length preceding AI could improve the probability of pregnancy.

In all, $41.7 \%$ of the AI events was preceded by elevated P4c pre-AI (between 0.5 and $5.0 \mathrm{ng} / \mathrm{mL}$ ), and $17.0 \%$ of AI was followed by a rapid increase in P4c between 3 and $6 \mathrm{~d}$ post-AI, both factors associated with reduced probability of pregnancy. These factors could be related to an imprecision of the IMAS biomodel in detecting the actual day of luteolysis, affecting the precision of AI. This could occur in cows that do not follow the P4c profile expected by the biomodel (e.g., prolonged estrous cycle length or different individual thresholds of milk P4c indicative of luteal activity). Elevated P4c pre-AI and a rapid increase in $\mathrm{P} 4 \mathrm{c}$ post-AI could also occur if a cow had an incomplete luteolysis. If elevated $\mathrm{P} 4 \mathrm{c}$ pre-AI is at least a partial manifestation of incomplete luteolysis, it may be hypothesized that giving exogenous $\mathrm{PGF}_{2 \alpha}$ when $\mathrm{P} 4 \mathrm{c}$ pre- $\mathrm{AI}$ is $>0.5 \mathrm{ng} / \mathrm{mL}$ will decrease $\mathrm{P} 4 \mathrm{c}$ near the time of $\mathrm{AI}$, thereby improving fertility. In support of this hypothesis, Ambrose et al. (2015) observed improved conception rates in cows that received a low dose of $\mathrm{PGF}_{2 \alpha}$ (10 mg of dinoprost) concurrent with AI following a synchronization protocol. Conversely, Sauls et al. (2018) evaluated the effects of a similar $\mathrm{PGF}_{2 \alpha}$ treatment administered at timed-AI and found no effects on pregnancy per AI.

In the present study, $16.9 \%$ of $\mathrm{AI}$ was followed by a delayed onset of luteal phase beyond $12 \mathrm{~d}$ post-AI, which lowered $\mathrm{P} 4 \mathrm{c}$ at early diestrus and was negatively associated with the probability of pregnancy. In view of this finding, another potential strategy is to administer exogenous GnRH near the time of AI to synchronize ovulation (Pursley et al., 1995), to reduce the incidence of delayed onset of luteal activity post-AI and improve fertility.

Based on the ROC cut-points used to characterize variables associated with reduced fertility in the present study, the prevalence of sub-optimal $\mathrm{P} 4 \mathrm{c}$ at mid $(\leq 12.4 \mathrm{ng} / \mathrm{mL})$ and late diestrus $(\leq 22.7 \mathrm{ng} / \mathrm{mL})$ were 27.5 and $51.4 \%$, respectively. A moderate positive relationship $(P<0.001)$ existed between $\mathrm{P} 4 \mathrm{c}$ at both mid and late diestrus $(\mathrm{r}=0.43)$. Among the $\mathrm{P} 4 \mathrm{c}$ profiles that had a sub-optimal P4c at mid diestrus, $77.0 \%$ also had sub-optimal P4c at late diestrus; both factors were associated with reduced fertility. Interestingly, the parameter that had the greatest probability of pregnancy $(41.5 \%)$ was $\mathrm{P} 4 \mathrm{c}$ slope to late diestrus of $>6.7$ $\mathrm{ng} / \mathrm{mL}$ (Q4, Table 6), indicating that a rapid increase 
rate in $\mathrm{P} 4 \mathrm{c}$ between early and late diestrus (between approximately 5 and $14 \mathrm{~d}$ post-AI) is highly beneficial to fertility.

Several studies have investigated the effects of supplementing P4 post-AI on fertility and reported inconsistent results, such as positive (Garcia-Ispierto and López-Gatius, 2017), negative (Parr et al., 2014), or no association (Colazo et al., 2013). Although the conditions among studies varied (i.e., breed, P4 dose, day of cycle when $\mathrm{P} 4$ was administered), our results provide an insight that cows that benefited from $\mathrm{P} 4$ supplementation in previous studies might be those that had sub-optimal $\mathrm{P} 4 \mathrm{c}$ at different time points after AI. In this regard, monitoring real-time $\mathrm{P} 4 \mathrm{c}$ profiles provides an opportunity to strategically supplement $\mathrm{P} 4$ in cows with sub-optimal P4c post-AI. Future studies should explore factors associated with sub-optimal P4c and evaluate potential benefits associated with strategic hormonal interventions. Moreover, refinement of the IMAS biomodel to improve its precision will also be of value to optimize reproductive performance in herds monitoring in-line milk $\mathrm{P} 4 \mathrm{c}$ profiles.

In conclusion, we characterized parameters of luteal activity associated with reduced probability of pregnancy that could be used as benchmarks in herds monitoring in-line milk P4c profiles in dairy cows. Such parameters include prolonged luteal phase preceding AI, delayed onset of luteal phase post-AI, and suboptimal P4c before and after AI. Recommendations such as targeted hormonal interventions remain to be tested in cows with luteal activity parameters that are negatively associated with the probability of pregnancy. The in-line milk P4 analysis system, a relatively new tool for reproductive management of dairy herds, warrants further evaluations to optimize the precision of sampling frequency and timing of AI to improve reproductive performance.

\section{ACKNOWLEDGMENTS}

This study was supported by Alberta Milk and the Strategic Research and Development Program, Alberta Agriculture and Forestry (Agriculture Funding Consortium Grant \#2016F056R). The authors thank DeLaval Canada and Lattec I/S for their technical support with the data collection and the owners of the commercial dairy farms involved in the study for their cooperation.

\section{REFERENCES}

Adriaens, I., W. Saeys, T. Huybrechts, C. Lamberigts, L. François, K. Geerinckx, J. Leroy, B. De Ketelaere, and B. Aernouts. 2018. A novel system for on-farm fertility monitoring based on milk progesterone. J. Dairy Sci. 101:8369-8382. https://doi.org/10.3168/ jds.2017-13827.
Ambrose, D. J., M. Gobikrushanth, S. Zuidhof, and J. P. Kastelic. 2015. Low-dose natural prostaglandin F2a (dinoprost) at timed insemination improves conception rate in dairy cattle. Theriogenology 83:529-534. https://doi.org/10.1016/j.theriogenology.2014.10 .034 .

Bisinotto, R. S., M. B. Pansani, L. O. Castro, C. D. Narciso, L. D. P. Sinedino, N. Martinez, P. E. Carneiro, W. W. Thatcher, and J. E. P. Santos. 2015. Effect of progesterone supplementation on fertility responses of lactating dairy cows with corpus luteum at the initiation of the Ovsynch protocol. Theriogenology 83:257-265. https:/ /doi.org/10.1016/j.theriogenology.2014.09.021.

Bisinotto, R. S., E. S. Ribeiro, F. S. Lima, N. Martinez, L. F. Greco, L. F. S. P. Barbosa, P. P. Bueno, L. F. S. Scagion, W. W. Thatcher, and J. E. P. Santos. 2013. Targeted progesterone supplementation improves fertility in lactating dairy cows without a corpus luteum at the initiation of the timed artificial insemination protocol. J. Dairy Sci. 96:2214-2225. https://doi.org/10.3168/jds.2012-6038.

Bleach, E. C. L., R. G. Glencross, and P. G. Knight. 2004. Association between ovarian follicle development and pregnancy rates in dairy cows undergoing spontaneous oestrous cycles. Reproduction 127:621-629. https://doi.org/10.1530/rep.1.00190.

Bruinjé, T. C., M. G. Colazo, M. Gobikrushanth, and D. J. Ambrose. 2017a. Relationships among early postpartum luteal activity, parity, and insemination outcomes based on in-line milk progesterone profiles in Canadian Holstein cows. Theriogenology 100:32-41. https://doi.org/10.1016/j.theriogenology.2017.05.021.

Bruinjé, T. C., M. Gobikrushanth, M. G. Colazo, and D. J. Ambrose. 2017b. Dynamics of pre- and post-insemination progesterone profiles and insemination outcomes determined by an in-line milk analysis system in primiparous and multiparous Canadian Holstein cows. Theriogenology 102:147-153. https://doi.org/10.1016/ j.theriogenology.2017.05.024.

Cerri, R., R. Chebel, F. Rivera, C. Narciso, R. Oliveira, W. Thatcher, and J. Santos. 2011. Concentration of progesterone during the development of the ovulatory follicle: II. Ovarian and uterine responses. J. Dairy Sci. 94:3352-3365. https://doi.org/10.3168/jds $.2010-3735$.

Colazo, M. G., A. Dourey, R. Rajamahendran, and D. J. Ambrose. 2013. Progesterone supplementation before timed AI increased ovulation synchrony and pregnancy per AI, and supplementation after timed AI reduced pregnancy losses in lactating dairy cows. Theriogenology 79:833-841. https://doi.org/10.1016/j theriogenology.2012.12.011.

Colazo, M. G., I. López Helguera, A. Behrouzi, D. J. Ambrose, and R. J. Mapletoft. 2017. Relationship between circulating progesterone at timed-AI and fertility in dairy cows subjected to GnRH-based protocols. Theriogenology 94:15-20. https://doi.org/10.1016/j .theriogenology.2017.02.004.

DeLaval International. 2011. Herd Navigator ${ }^{\mathrm{TM}}$ and reproduction management. Accessed Jul. 8, 2015. http://delaval-com-www .gtm.episerverhosting.com/PageFiles/171203/53571175_HN Reproduktion managementLOWRES.pdf.

Dransfield, M. B. G., R. L. Nebel, R. E. Pearson, and L. D. Warnick. 1998. Timing of insemination for dairy cows identified in estrus by a radiotelemetric estrus detection system. J. Dairy Sci. 81:18741882. https://doi.org/10.3168/jds.S0022-0302(98)75758-3.

Friggens, N. C., M. Bjerring, C. Ridder, S. Højsgaard, and T. Larsen. 2008. Improved detection of reproductive status in dairy cows using milk progesterone measurements. Reprod. Domest. Anim. 43:113-121. https://doi.org/10.1111/j.1439-0531.2008.01150.x.

Friggens, N. C., and M. G. G. Chagunda. 2005. Prediction of the reproductive status of cattle on the basis of milk progesterone measures: Model description. Theriogenology 64:155-190. https:// doi.org/10.1016/j.theriogenology.2004.11.014.

Garcia-Ispierto, I., and F. López-Gatius. 2017. Progesterone supplementation in the early luteal phase after artificial insemination improves conception rates in high-producing dairy cows. Theriogenology 90:20-24. https://doi.org/10.1016/j.theriogenology.2016 .11 .006 .

Garrett, J. E., R. D. Geisert, M. T. Zavy, and G. L. Morgan. 1988. Evidence for maternal regulation of early conceptus growth and 
development in beef cattle. J. Reprod. Fertil. 84:437-446. https:// doi.org/10.1530/jrf.0.0840437.

Geisert, R., G. Morgan, E. Short, and M. Zavy. 1992. Endocrine events associated with endometrial function and conceptus development in cattle. Reprod. Fertil. Dev. 4:301-305. https://doi.org/10.1071/ RD9920301.

Hommeida, A., T. Nakao, and H. Kubota. 2004. Luteal function and conception in lactating cows and some factors influencing luteal function after first insemination. Theriogenology 62:217-225. https://doi.org/10.1016/j.theriogenology.2003.09.018.

Lamming, G. E., and A. O. Darwash. 1998. The use of milk progesterone profiles to characterise components of subfertility in milked dairy cows. Anim. Reprod. Sci. 52:175-190. https://doi.org/10 .1016/S0378-4320(98)00099-2.

LeBlanc, S. J. 2013. Is a high level of milk production compatible with good reproductive performance in dairy cows? Anim. Front. 3:84-91. https://doi.org/10.2527/af.2013-0038.

Lopez, H., L. D. Satter, and M. C. Wiltbank. 2004. Relationship between level of milk production and estrous behavior of lactating dairy cows. Anim. Reprod. Sci. 81:209-223. https://doi.org/10 .1016/j.anireprosci.2003.10.009.

Lucy, M. C. 2001. Reproductive loss in high-producing dairy cattle: Where will it end? J. Dairy Sci. 84:1277-1293. https://doi.org/10 .3168/jds.S0022-0302(01)70158-0.

Opsomer, G., M., H. Coryn, Deluyker, and A. de Kruif. 1998. An analysis of ovarian dysfunction in high yielding dairy cows after calving based on progesterone profiles. Reprod. Domest. Anim. 33:193-204. https://doi.org/10.1111/j.1439-0531.1998.tb01342.x.

Parr, M. H., M. A. Crowe, P. Lonergan, A. C. O. Evans, D. Rizos, and M. G. Diskin. 2014. Effect of exogenous progesterone supplementation in the early luteal phase post-insemination on pregnancy per artificial insemination in Holstein-Friesian cows. Anim. Reprod. Sci. 150:7-14. https://doi.org/10.1016/j.anireprosci.2014.08.008.

Pope, G. S., I. Majzlik, P. J. H. Ball, and J. D. Leaver. 1976. Use of progesterone concentrations in plasma and milk in the diagnosis of pregnancy in domestic cattle. Br. Vet. J. 132:497-506. https://doi .org/10.1016/S0007-1935(17)34587-6.

Pursley, J. R., M. O. Mee, and M. C. Wiltbank. 1995. Synchronization of ovulation in dairy cows using PGF2 $\alpha$ and GnRH. Theriogenology 44:915-923. https://doi.org/10.1016/0093-691X(95)00279-H.

Pursley, J. R., R. W. Silcox, and M. C. Wiltbank. 1998. Effect of time of artificial insemination on pregnancy rates, calving rates, pregnancy loss, and gender ratio after synchronization of ovulation in lactating dairy cows. J. Dairy Sci. 81:2139-2144. https://doi.org/ 10.3168/jds.S0022-0302(98)75790-X.

Ranasinghe, R. M. S. B. K., T. Nakao, K. Yamada, K. Koike, A. Hayashi, and C. M. B. Dematawewa. 2011. Characteristics of prolonged luteal phase identified by milk progesterone concentrations and its effects on reproductive performance in Holstein cows. J. Dairy Sci. 94:116-127. https://doi.org/10.3168/jds.2010-3213.

Remnant, J., M. Green, J. Huxley, and C. Hudson. 2016. What is the normal estrous cycle length for the modern dairy cow? Theriogenology 86:2334. https://doi.org/10.1016/j.theriogenology.2016 .08 .015 .

Remnant, J. G., M. J. Green, J. N. Huxley, and C. D. Hudson. 2015. Variation in the interservice intervals of dairy cows in the United Kingdom. J. Dairy Sci. 98:889-897. https://doi.org/10.3168/jds $.2014-8366$.

Ribeiro, E. S., K. N. Galvão, W. W. Thatcher, and J. E. P. Santos. 2012. Economic aspects of applying reproductive technologies to dairy herds. Anim. Reprod. 9:370-387.
Roelofs, J. B., F. J. C. M. Van Eerdenburg, W. Hazeleger, N. M. Soede, and B. Kemp. 2006. Relationship between progesterone concentrations in milk and blood and time of ovulation in dairy cattle. Anim. Reprod. Sci. 91:337-343. https://doi.org/10.1016/j .anireprosci.2005.04.015.

Sangsritavong, S., D. K. Combs, R. Sartori, L. E. Armentano, and M. C. Wiltbank. 2002. High feed intake increases liver blood flow and metabolism of progesterone and estradiol- $17 \beta$ in dairy cattle. J. Dairy Sci. 85:2831-2842. https://doi.org/10.3168/jds.S0022 $-0302(02) 74370-1$

Sartori, R., J. M. Haughian, R. D. Shaver, G. J. M. Rosa, and M. C. Wiltbank. 2004. Comparison of ovarian function and circulating steroids in estrous cycles of Holstein heifers and lactating cows. J. Dairy Sci. 87:905-920. https://doi.org/10.3168/jds.S0022 -0302(04)73235-X.

Sauls, J. A., B. E. Voelz, L. G. D. Mendonça, and J. S. Stevenson. 2018. Additional small dose of prostaglandin F $2 \alpha$ at timed artificial insemination failed to improve pregnancy risk of lactating dairy cows. Theriogenology. https://doi.org/10.1016/j.theriogenology 2017.12.051.

Savio, J. D., M. P. Boland, and J. F. Roche. 1990. Development of dominant follicles and length of ovarian cycles in post-partum dairy cows. J. Reprod. Fertil. 88:581-591. https://doi.org/10 $.1530 /$ jrf. 0.0880581 .

Stevenson, J. S., S. L. Hill, R. L. Nebel, and J. M. DeJarnette. 2014 Ovulation timing and conception risk after automated activity monitoring in lactating dairy cows. J. Dairy Sci. 97:4296-4308. https://doi.org/10.3168/jds.2013-7873.

Stronge, A. J. H., J. M. Sreenan, M. G. Diskin, J. F. Mee, D. A Kenny, and D. G. Morris. 2005. Post-insemination milk progesterone concentration and embryo survival in dairy cows. Theriogenology $64: 1212-1224$. https://doi.org/10.1016/j.theriogenology.2005 .02 .007 .

Tenghe, A. M. M., A. C. Bouwman, B. Berglund, E. Strandberg, J. Y. Blom, and R. F. Veerkamp. 2015. Estimating genetic parameters for fertility in dairy cows from in-line milk progesterone profiles. J. Dairy Sci. 98:5763-5773. https://doi.org/10.3168/jds.2014-8732.

Valenza, A., J. O. Giordano, G. Lopes, L. Vincenti, M. C. Amundson, and P. M. Fricke. 2012. Assessment of an accelerometer system for detection of estrus and treatment with gonadotropin-releasing hormone at the time of insemination in lactating dairy cows. J. Dairy Sci. 95:7115-7127. https://doi.org/10.3168/jds.2012-5639.

van Cleeff, J., M. C. Lucy, C. J. Wilcox, and W. W. Thatcher. 1992 Plasma and milk progesterone and plasma LH in ovariectomized lactating cows treated with new or used controlled internal drug release devices. Anim. Reprod. Sci. 27:91-106. https://doi.org/10 .1016/0378-4320(92)90049-J.

Vieira-Neto, A., K. N. Galvão, W. W. Thatcher, and J. E. P. Santos. 2017. Association among gestation length and health, production, and reproduction in Holstein cows and implications for their offspring. J. Dairy Sci. 100:3166-3181. https://doi.org/10.3168/jds .2016-11867.

Wiltbank, M., H. Lopez, and R. Sartori. 2006. Changes in reproductive physiology of lactating dairy cows due to elevated steroid metabolism. Theriogenology 65:17-29. https://doi.org/10.1016/j .theriogenology.2005.10.003.

Wiltbank, M. C., A. H. Souza, J. O. Giordano, A. B. Nascimento, J. M. Vasconcelos, R. S. Surjus, P. D. Carvalho, R. W. Bender, and R. Sartori. 2012. Positive and negative effects of progesterone during timed AI protocols in lactating dairy cattle. Anim. Reprod. 9:231-241. 